\title{
The isotopic composition of methane in the stratosphere: high-altitude balloon sample measurements
}

\author{
T. Röckmann ${ }^{1,2}$, M. Brass ${ }^{1,2}$, R. Borchers ${ }^{3}$, and A. Engel $^{4}$ \\ ${ }^{1}$ Institute for Marine and Atmospheric Research Utrecht, Utrecht University, Utrecht, The Netherlands \\ ${ }^{2}$ Atmospheric Physics Division, Max Planck Institute for Nuclear Physics, Heidelberg, Germany \\ ${ }^{3}$ Planets and Comets Department, Max Planck Institute for Solar System Research, Katlenburg-Lindau, Germany \\ ${ }^{4}$ Institute for Atmospheric and Environmental Sciences, J. W. Goethe University, Frankfurt, Germany \\ Received: 17 February 2011 - Published in Atmos. Chem. Phys. Discuss.: 19 April 2011 \\ Revised: 9 December 2011 - Accepted: 12 December 2011 - Published: 21 December 2011
}

\begin{abstract}
The isotopic composition of stratospheric methane has been determined on a large suite of air samples from stratospheric balloon flights covering subtropical to polar latitudes and a time period of $16 \mathrm{yr}$. 154 samples were analyzed for $\delta^{13} \mathrm{C}$ and 119 samples for $\delta \mathrm{D}$, increasing the previously published dataset for balloon borne samples by an order of magnitude, and more than doubling the total available stratospheric data (including aircraft samples) published to date. The samples also cover a large range in mixing ratio from tropospheric values near $1800 \mathrm{ppb}$ down to only $250 \mathrm{ppb}$, and the strong isotope fractionation processes accordingly increase the isotopic composition up to $\delta^{13} \mathrm{C}=-14 \%$ and $\delta \mathrm{D}=+190 \%$ o, the largest enrichments observed for atmospheric $\mathrm{CH}_{4}$ so far. When analyzing and comparing kinetic isotope effects (KIEs) derived from single balloon profiles, it is necessary to take into account the residence time in the stratosphere in combination with the observed mixing ratio and isotope trends in the troposphere, and the range of isotope values covered by the individual profile. The isotopic composition of $\mathrm{CH}_{4}$ in the stratosphere is affected by both chemical and dynamical processes. This severely hampers interpretation of the data in terms of the relative fractions of the three important sink mechanisms (reaction with $\mathrm{OH}, \mathrm{O}\left({ }^{1} \mathrm{D}\right)$ and $\left.\mathrm{Cl}\right)$. It is shown that a formal sink partitioning using the measured data severely underestimates the fraction removed by $\mathrm{OH}$, which is likely due to the insensitivity of the measurements to the kinetic fractionation in the lower stratosphere. Full quantitative interpretation of the $\mathrm{CH}_{4}$ isotope data in terms of the three sink reactions requires a global model.
\end{abstract}

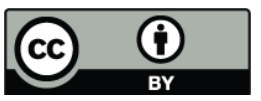

Correspondence to: T. Röckmann (t.roeckmann@uu.nl)

\section{Introduction}

In the well-mixed troposphere, the $\mathrm{CH}_{4}$ mixing ratio and its isotopic composition are determined by the principal balance between the sources (and their isotopic signatures) and sinks (and the corresponding kinetic fractionation factors) (Stevens and Rust, 1982; Quay et al., 1999; Miller et al., 2002). For a long-lived gas as methane, this leads to rather stable mixing ratio and isotope values throughout the troposphere that are modulated by the seasonal variations in the production and destruction rates and long-term temporal trends, resulting from disequilibrium of production and removal (Stevens and Rust, 1982; Lowe et al., 1997; Bergamaschi et al., 1998, 2000, 2001; Quay et al., 1999; Tyler et al., 1999; Miller et al., 2002; Tarasova et al., 2006).

In the stratosphere the situation is different, since the only source for stratospheric methane is the tropospheric flux into the stratosphere, occurring mainly in the tropics. In the absence of in situ sources $\mathrm{CH}_{4}$ mixing ratios decrease strongly in the stratosphere due to the removal by the three chemical (1st order) reactions with $\mathrm{OH}, \mathrm{O}\left({ }^{1} \mathrm{D}\right)$ and $\mathrm{Cl}$ (Wahlen et al., 1989; Wahlen, 1993; Brenninkmeijer et al., 1995; Irion et al., 1996; Sugawara et al., 1997; Ridal and Siskind, 2002; McCarthy et al., 2003; Rice et al., 2003). Removal of $\mathrm{CH}_{4}$ by photolysis becomes important only in the mesosphere. However, throughout most of the stratosphere, the local chemical removal rates of $\mathrm{CH}_{4}$ are actually slower than typical transport times (Zahn et al., 2006). Consequently, the $\mathrm{CH}_{4}$ mixing ratio and its isotopic composition in an air parcel is dependent on the reaction with $\mathrm{OH}, \mathrm{O}\left({ }^{1} \mathrm{D}\right)$ and $\mathrm{Cl}$ (chemical removal) on the one hand and its pathway through the stratosphere (physical transport, dynamics, see Sect. 2) on the other hand. In general, the longer the residence time of an air mass in the stratosphere, the more it is processed photochemically and the more $\mathrm{CH}_{4}$ has been removed.

Published by Copernicus Publications on behalf of the European Geosciences Union. 
As $\mathrm{CH}_{4}$ is not fully oxidized in the stratosphere, but a large fraction returns to the troposphere, the isotope effects in the stratosphere have a significant effect on the tropospheric $\mathrm{CH}_{4}$ isotope budget (Gupta et al., 1996; McCarthy et al., 2001; Wang et al., 2002).

Only a limited number of data on isotopic composition of stratospheric methane have been previously published. Sugawara et al. (1997) presented one $\delta^{13} \mathrm{C}$ profile from a balloon flight over Japan in 1994 and Rice et al. (2003) presented $\delta^{13} \mathrm{C}$ and $\delta \mathrm{D}$ values from various flights with the highaltitude aircraft ER-2 between 1996-2000 up to $21 \mathrm{~km}$. Furthermore, Brenninkmeijer et al. $(1995,1996)$ published few $\delta^{13} \mathrm{C}$ data obtained on aircraft flights between New Zealand and Antarctica.

In this paper we present data from 13 stratospheric balloon flights, which increase the number of balloon observations in the literature by more than an order of magnitude and the number of total published data for the stratosphere by a factor of more than 2.

\section{Short review of stratospheric dynamics and its effect on tracer distributions}

After air enters the stratosphere, mainly in the tropics, it is first transported upwards in the tropics and then polewards and downwards, and it descends back to the troposphere at higher latitudes. The turnaround time for this global meridional circulation, the so-called Brewer-Dobson-circulation (BDC, Dobson et al., 1946; Brewer, 1949) is several years for the middle and upper stratosphere (Boering et al., 1996). Next to this so-called deep branch of the BDC, which dominates the middle stratosphere, a shallow branch exists in which air is transported more directly from the tropics to the extratropics, without passing through high altitudes (Birner and Bönisch, 2011; Bönisch et al., 2011). The Brewer Dobson circulation is a combination of the net residual transport described above with fast mixing along isentropes. The global distributions and the surfaces of constant mixing ratio (isopleths) of long lived tracers are thus a result of two effects. First, the meridional net circulation lifts the tracer isopleths in the tropics and depresses them at high-latitudes and second, the quasi-horizontal mixing equilibrates the tracer distribution along the isentropes. For long-lived tracers, the fast quasi-horizontal mixing forms rapid exchange surfaces, common to all (sufficiently) long-lived tracers, on which local deviations are homogenized. As a consequence two longlived tracers will form a compact relation in a tracer:tracer plot, i.e. ideally a single curve for the correlation of their mixing ratios (Holton, 1986; Mahlman et al., 1986; Plumb and Ko, 1992). This idealized model is sometimes referred to as "global mixing scheme". It has successively been extended to better describe the situation in the tropics. Subtropical barriers split the global isopleths into the hemispheric "surf zones" and a "tropical pipe" (Plumb, 1996; Andrews et al., 2001). The "leaky tropical pipe" model allows for recirculation of mid latitude air back into the tropics (Avallone and Prather, 1996; Volk et al., 1996; Neu and Plumb, 1999). The region below the tropical pipe corresponds to the shallow branch of the BDC where fast direct exchange between tropics and extratropics is possible.

The polar vortices are seasonal transport barriers that are not included in these general global transport schemes. The radiative cooling in the polar night and the stronger downward forcing from the BDC in winter leads to a large-scale subsidence of air from the upper stratosphere and even mesosphere, which stays substantially isolated from extra-vortex air. Thus, the vortex edge, similar to the subtropical barrier, is characterised by strong horizontal tracer and potential vorticity gradients and the tracer isopleths are no more "almost parallel" to isentropes. Several mechanisms are known or discussed for interaction between vortex and extra-vortex air. Waugh et al. (1997) showed the occurrence of "anomalous mixing" lines, i.e. deviating from the general compact tracer:tracer relation, and related them to end member mixing between vortex and mid-latitudes. Plumb et al. (2000) offered two alternative mechanisms, a "continuous weak mixing" through the vortex edge and the intrusion of extra-vortex air in a single (or multiple) event(s) throughout the phase of descent, and its subsequent vertical redistribution inside the vortex. Such an intrusion was used in Engel et al. (2006) to explain the enclosure of mesospheric air observed in stratospheric balloon samples. With increasing solar heating after the polar night, the latitudinal temperature gradient, circumpolar jet, wave activities, and vortex isolation decrease and vortex air dissipates into the surrounding extra-vortex region (WMO, 2003). How the dynamical properties of the stratosphere affect the mixing ratio and isotopic composition of $\mathrm{CH}_{4}$ will be discussed in detail in Sects. 5 and 6.3.

\section{Experimental}

High-altitude samples (up to $35 \mathrm{~km}$ ) from stratospheric balloon borne air samplers were provided by the Max-PlanckInstitut (MPI) für Sonnensystemforschung (formerly MaxPlanck-Institut für Aeronomie), Katlenburg-Lindau, Germany and the Institut für Atmosphäre und Umwelt (formerly Institut für Meteorologie und Geophysik), Universität Frankfurt, Germany. The samplers from both groups consist of 15 electro-polished stainless steel tubes immersed into liquid neon at a temperature of $27 \mathrm{~K}$, but differ especially in the intake design (Schmidt et al., 1987). The sampling tubes have an internal volume of about $0.5 \mathrm{dm}^{3}$ that is filled to pressures between $\sim 5$ to 50 bar (at room temperature). The vertical sampling resolution is usually about $1 \mathrm{~km}$, sampling latitudes are essentially invariant, and longitude variations can be a few degrees, depending on the prevailing zonal winds during sample collection. 
Table 1. Measured and calculated kinetic isotope effects and coefficients for their temperature dependence $\operatorname{KIE}(T)=A \exp (B / T)$.

\begin{tabular}{|c|c|c|c|c|c|c|c|}
\hline & $\mathrm{KIE}^{13} \mathrm{C}_{(T=296 \mathrm{~K})}$ & $T$ & $A$ & $B$ & $\mathrm{KIE}^{13} \mathrm{C}(T=223 \mathrm{~K})$ & & \\
\hline $\mathrm{OH}$ & $1.0039 \pm 0.0004$ & & $?$ & $?$ & & & Saueressig et al. (2001) \\
\hline $\mathrm{O}\left({ }^{1} \mathrm{D}\right)$ & 1.013 & $223-295$ & & 0 & 1.013 & meas. & Saueressig et al. (2001) \\
\hline \multirow[t]{2}{*}{$\mathrm{Cl}$} & $1.066 \pm 0.02$ & $223-297$ & 1.043 & 6.455 & $1.075 \pm 0.005$ & meas. & Saueressig et al. (1995) \\
\hline & $\mathrm{KIE}^{\mathrm{D}}$ & & & & $\mathrm{KIE}^{\mathrm{D}}$ & & \\
\hline $\mathrm{OH}$ & $1.294 \pm 0.018$ & & $1.097^{*}$ & $49 \pm 22$ & 1.367 & calc. & Saueressig et al. (2001) \\
\hline $\mathrm{O}\left({ }^{1} \mathrm{D}\right)$ & $1.066 \pm 0.002$ & $224-295$ & & 0 & 1.06 & meas. & Saueressig et al. (2001) \\
\hline $\mathrm{Cl}$ & $1.508 \pm 0.04$ & $223-295$ & 1.278 & $51.31 \pm 19.1$ & 1.61 & meas. & Saueressig et al. (1996) \\
\hline
\end{tabular}

* Adjusted T-dependence from (Gierzak et al., 1997) to match room temperature measurement.

The MPI group had stored a large number of stratospheric air samples from scientific balloon flights covering more than a decade (1987-1999) as stratospheric air archive. These samples were made available for isotope analysis on longlived greenhouse gases. From 2000 to 2003, samples from 5 more stratospheric flights with the BONBON cryogenic sampler operated by the Universität Frankfurt group were analyzed. Those samples were measured within few months after the flight. Table 2 gives an overview of the exact sampling dates and locations.

Mixing ratio and isotopic composition of the air samples were determined on a high-precision continuous flow isotope ratio mass spectrometry system (Brass and Röckmann, 2010) that has been used in various studies to determine the isotopic composition of $\mathrm{CH}_{4}$ (Keppler et al., 2006, 2008; Tarasova et al., 2006; Vigano et al., 2009, 2010). The samples are analyzed automatically relative to a laboratory standard air cylinder that is usually measured after each two samples. The reproducibility of the system, as determined from extensive tests, including subsets of the stratospheric samples presented here, is $18 \mathrm{ppb}$ for $\mathrm{CH}_{4}$ mixing ratios, $0.07 \%$ o for $\delta^{13} \mathrm{C}$ and $2.3 \%$ for $\delta \mathrm{D}$ (Brass and Röckmann, 2010). For $\delta^{13} \mathrm{C}$ analysis we use the peak integration routine of the standard ISODAT software package, for $\delta \mathrm{D}$ an improved peak integration software has been developed (Brass and Röckmann, 2010). Isotope ratios are reported in the common $\delta$ notation relative to the international standard materials Vienna PeeDeeBelemnite for $\delta^{13} \mathrm{C}$ and Vienna Standard Mean Ocean Water for $\delta \mathrm{D} . \mathrm{CH}_{4}$ mixing ratios are reported on the NOAA04 scale (Dlugokencky et al., 2005). Most samples were attached to the analytical system directly from the original sampling containers, only a subset of samples was first expanded into 21 volume stainless steel flasks and analyzed later.

\section{Results}

\subsection{General classification of flight profiles}

Figure 1a shows the full set of methane mixing ratio profiles obtained from the balloon flights. As outlined in the introduction, mixing ratios decrease from tropospheric levels with altitude and latitude in the stratosphere. This is due to $\mathrm{CH}_{4}$ destruction related to the photochemical processing of stratospheric air and the global transport and mixing patterns outlined in Sect. 2. The extent of chemical removal is clearly different for the individual profiles and the samples split into three groups, roughly according to the flight latitude, i.e. high latitudes (polar, here Arctic), mid latitudes and subtropics.

Generally, the $\delta^{13} \mathrm{C}$ and $\delta \mathrm{D}$ vertical profiles mirror the mixing ratio profiles (lower mixing ratio corresponds to higher $\delta$-values) and therefore they generally show similar structural variations (Fig. $1 \mathrm{~b}$ and c). The $\delta$-values increase with altitude and latitude. Vortex air, with its very low $\mathrm{CH}_{4}$ content, shows the highest isotope enrichments. The degree of this enrichment depends on the extent of photochemical processing in the stratosphere.

While previous measurements (Rice et al., 2003) cover mixing ratios between $700-1800 \mathrm{ppb}$ with $\delta^{13} \mathrm{C}$ reaching from tropospheric values $\sim-48 \%$ to $-34 \%$, and $\delta \mathrm{D}$ from $-90 \%$ to $\sim+26 \%$, respectively, this work considerably extends the range of available data, to $\mathrm{CH}_{4}$ mixing ratios down to $\sim 250 \mathrm{ppb}$, corresponding to values up to $-13.7 \%$ o for $\delta^{13} \mathrm{C}$ and $+190 \%$ for $\delta \mathrm{D}$.

\subsubsection{Polar profiles}

The Arctic samples (all collected using Kiruna as operational base) show additional differences for different sampling seasons. The winter samples (KIR-92-01, -02, -03, KIR-00-01, KIR-03-03) reflect the presence of the polar vortex. Air that descends in the vortex has undergone massive methane oxidation. These profiles are characterised by the occurrence of very low $\mathrm{CH}_{4}$ mixing ratios (down to $\sim 250 \mathrm{ppb}$ ) and strong 
Table 2. Overview of balloon flights and number of samples analyzed for $\delta^{13} \mathrm{C}$ and $\delta \mathrm{D}$ (column ${ }^{13} \mathrm{C}$ and $\mathrm{D}$ ). Each flight is given a flight ID as STA-JJ-MM, where STA is the 3-letter-code for the balloon launch station, JJ the year and MM the month of sampling.

\begin{tabular}{llllll}
\hline Flight ID & Flight date & Location & ${ }^{13} \mathrm{C}$ & $\mathrm{D}$ & Characteristics \\
\hline \multicolumn{5}{c}{ Flights operated by MPI für Sonnensystemforschung } \\
\hline HYD-87-03 & $03 / 26 / 87$ & HYD $^{1}$ & 5 & 5 & Subtropical \\
KIR-92-01 & $01 / 18 / 92$ & KIR $^{2}$ & 13 & 13 & Arctic weak vortex, final warming series \\
KIR-92-02 & $02 / 06 / 92$ & KIR $^{2}$ & 10 & 10 & final warming series \\
KIR-92-03 & $03 / 20 / 92$ & KIR $^{2}$ & 10 & 9 & final warming series \\
ASA-93-09 & $09 / 30 / 93$ & ASA $^{3}$ & 15 & 15 & mid-latitudinal background \\
KIR-95-03 & $03 / 07 / 95$ & KIR $^{2}$ & 11 & 11 & Arctic with mid-latitudinal characteristics \\
HYD-99-04 & $04 / 29 / 99$ & HYD $^{1}$ & 10 & 9 & Subtropical \\
GAP-99-06 & $06 / 23 / 99$ & GAP $^{4}$ & 15 & 15 & mid-latitudinal summer \\
\hline
\end{tabular}

Flights operated by Institut für Meteorologie und Geophysik, Universität Frankfurt

\begin{tabular}{llllll}
\hline KIR-00-01 & $01 / 03 / 00$ & KIR $^{2}$ & 13 & $-^{5}$ & Arctic strong vortex \\
ASA-01-10 & $10 / 11 / 01$ & $\mathrm{ASA}^{3}$ & 13 & $-^{5}$ & mid-latitudinal background \\
ASA-02-09 & $09 / 15 / 02$ & $\mathrm{ASA}^{3}$ & 13 & 6 & mid-latitudinal background \\
KIR-03-03 & $03 / 06 / 03$ & $\mathrm{KIR}^{2}$ & 13 & 13 & Arctic vortex, mesospheric enclosure \\
KIR-03-06 & $06 / 09 / 03$ & $\mathrm{KIR}^{2}$ & 13 & 13 & Arctic summer \\
\hline
\end{tabular}

${ }^{1}$ HYD: Hyderabad, India $\left(17.5^{\circ} \mathrm{N}, 78.60^{\circ} \mathrm{E}\right) ;^{2} \mathrm{KIR}$ : Kiruna, Sweden $\left(67.9^{\circ} \mathrm{N}, 21.10^{\circ} \mathrm{E}\right) ;^{3}$ ASA: Aire sur l'Adour, France $\left(43.70^{\circ} \mathrm{N},-0.30^{\circ} \mathrm{E}\right){ }^{4}$ GAP: Gap, France $\left(44.44^{\circ} \mathrm{N}\right.$, $\left.6.14^{\circ} \mathrm{E}\right) ;{ }^{5} \delta \mathrm{D}$ analyses not fully developed at that time.

isotope enrichments. The spring and summer profiles (KIR95-03, KIR-03-06) are similar to mid-latitudinal profiles.

The balloon profile KIR-03-03 shows a distinct feature, i.e. above $24 \mathrm{~km}$ the $\mathrm{CH}_{4}$ mixing ratio increases and above $23 \mathrm{~km} \delta^{13} \mathrm{C}$ and $\delta \mathrm{D}$ decrease again with height. A detailed analysis of this flight, using several tracers, shows that at least the two samples above this $\mathrm{CH}_{4}$ minimum show clear mesospheric characteristics like high $\mathrm{CO}$ and $\mathrm{H}_{2}$ mixing ratios (Engel et al., 2006). Above those "mesospheric" samples, the air exhibits stratospheric characteristics again, and the methane mixing ratio and isotope data suggest that midlatitudinal air is mixed into the resolving vortex from above. The samples will be discussed in detail in Sect. 8.1.

\subsubsection{Mid-latitude profiles}

Four profiles from mid-latitudes are available (ASA-93-09, GAP-99-06, ASA-01-10, and ASA-02-09). Three flights took place in autumn and to some degree can be regarded as a stratospheric background. Photochemistry is decreased compared to summer and dynamical activity starts to intensify with the change from the summer to the winter circulation. All four profiles show wave structures in the vertical distribution of mixing ratio and isotopic composition with altitude, which indicate large-scale dynamical effects that disturb the smooth vertical evolution. In general, the mixing ratio and isotope values of the mid latitude flights are in the range of the Arctic summer profile (KIR-03-06), especially for altitudes above $20 \mathrm{~km}$.

\subsubsection{Subtropical profiles}

The subtropical region is represented by samples from two balloon flights from Hyderabad, India, HYD-87-03 and HYD-99-04. Methane mixing ratios are rather constant up to the tropopause at $18 \mathrm{~km}$ and slightly decrease above the tropopause, followed by a significant decrease starting at 20$23 \mathrm{~km}$. Only 5 samples were still available from the HYD87-03 flight, resulting in two groups of similar characteristics. Thus, this dataset alone holds only limited information. Compared to HYD-99-04 the HYD-87-03 profile is shifted to lower mixing ratios and looks similar to a mid-latitudinal profile. One has to take into account that $12 \mathrm{yr}$ passed between the two profiles. An age correction that takes the tropospheric trend into account will be applied in Sect. 6.1.

Sample HYD-99-04/15 is the highest altitude subtropical sample with a mixing ratio $\sim 1200 \mathrm{ppb}$ and an extremely high $\delta^{13} \mathrm{C}$-value (for a sample with $1200 \mathrm{ppb}$ ). When the balloon samples are compared to $\mathrm{CH}_{4}: \mathrm{N}_{2} \mathrm{O}$ tracer correlations for different latitude bins taken from (Michelsen et al., 1998), the tracer:tracer-plot identifies HYD-99-04/15 as the only deep tropical sample in the balloon set. However, this was one of the samples that were only available as an aliquot (not the original balloon sample container) and were analysed for $\delta^{13} \mathrm{C}$ only at the very beginning of measurement. Also the original container had rather low pressure. Since experimental problems cannot definitely be excluded, this sample will not be interpreted further. 

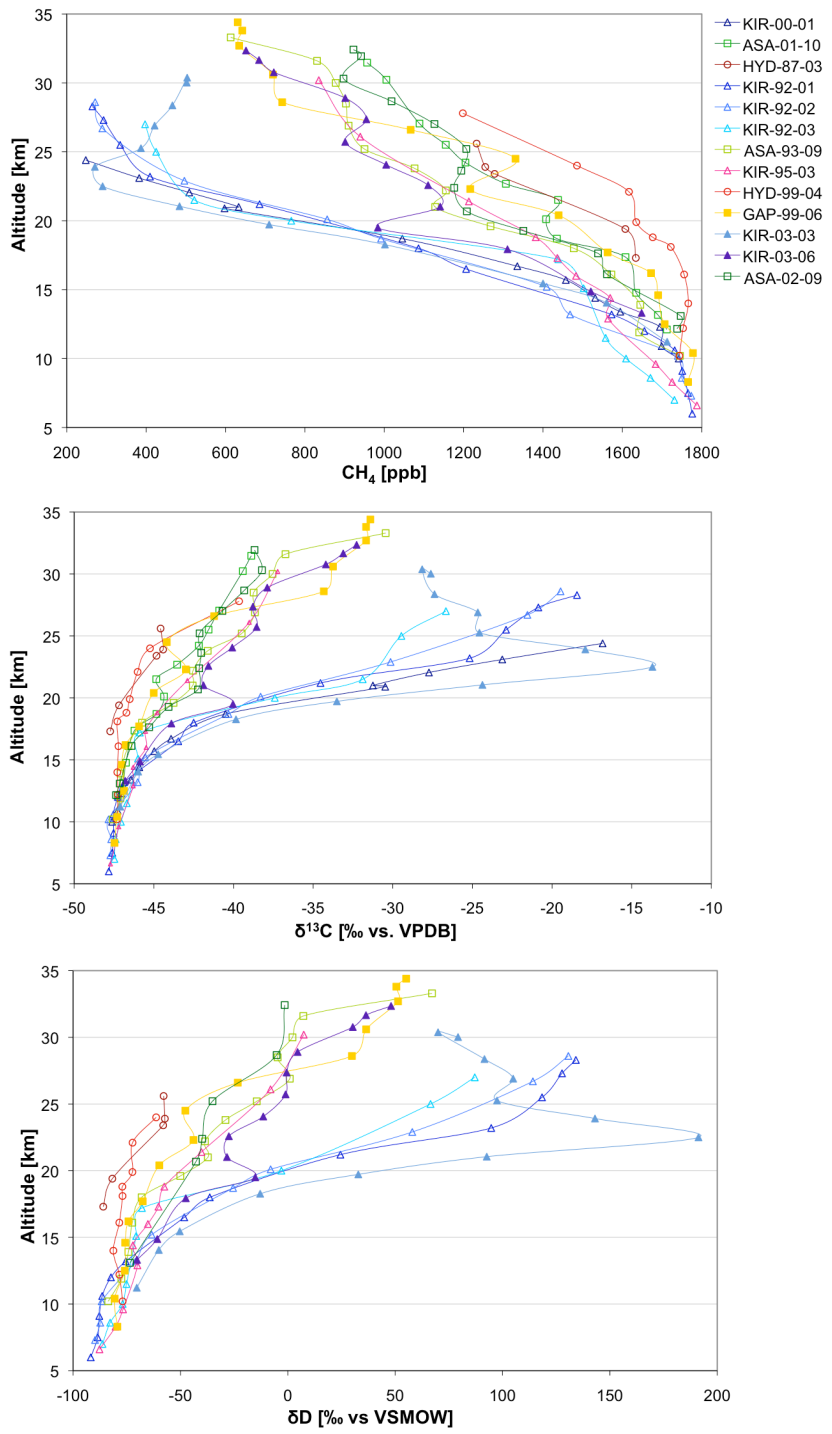

Fig. 1. Methane mixing ratio (a), $\delta^{13} \mathrm{C}(\mathbf{b})$ and $\delta \mathrm{D}$ (c) for all analysed balloon samples. $\Delta$ : Arctic samples (blue: vortex, purple: non-vortex, $\square$ : mid-latitudes (green, yellow), solid symbols: sampled in summer, $\bigcirc$ : tropics (red).

\subsection{Isotope - mixing ratio correlations}

It is obvious from Fig. 1 that there is considerable variability between the individual flight profiles. However, the variations in mixing ratio and isotopic composition are closely correlated, and it is useful and common to investigate isotope results as isotope - mixing ratio correlations (Fig. 2). Two points are remarkable in these correlations. First, each flight profile shows up as a relatively compact correlation curve and second, isotope-mixing ratio correlations are relatively stable over the full period of time, in different seasons and at various latitudinal regions (subtropics, mid-latitudes and polar). Thus, most of the variation observed in the vertical profiles disappears when $\delta$ values are discussed on the mixing ratio
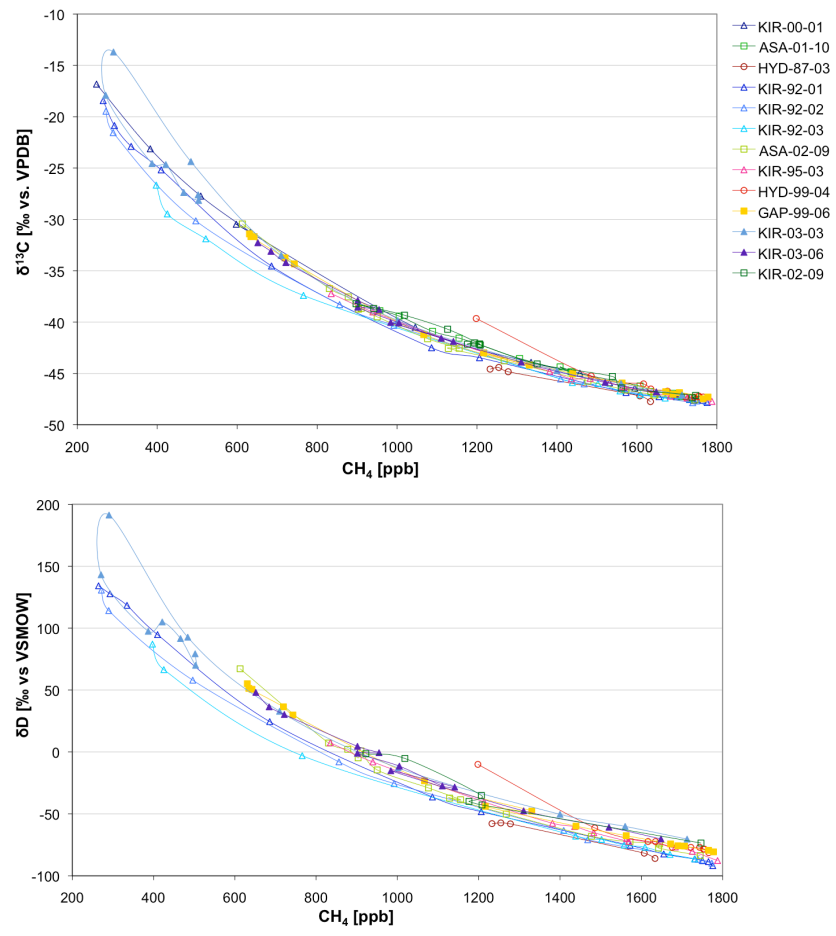

Fig. 2. Isotope:tracer relations $\delta(c)$ for the balloon data shown in Fig. 1.

scale (as alternative height coordinate) and the correlation curves can be regarded as (quasi) steady state functions for ${ }^{13} \mathrm{C}(c)$ and $\delta \mathrm{D}(c)$. Here and in the following, $c$ represents the mixing ratio.

The first observation reflects the previous finding that compact stratospheric tracer-tracer correlations occur for trace gases whose chemical removal time constants are larger than the transport time constants (Plumb and Ko, 1992), which is the case for the individual $\mathrm{CH}_{4}$ isotopologues. Thus this property can be explained by the global mixing scheme. The second observation shows the global validity of this scheme and that it is not strongly variable in time. This is expected, since $\mathrm{CH}_{4}$ is a long-lived trace gas with only small temporal trends since 1990 (e.g. Dlugokencky et al., 1998). From these correlations we can already conclude that no major changes in dynamics in the stratosphere and/or changes in the chemical sinks are observed.

Nevertheless, two areas of variability can be easily identified in Fig. 2: first, there is increased variability in both $\delta$ values for methane mixing ratios $<\sim 1000 \mathrm{ppb}$, which is mainly vortex or vortex edge air. For this region the assumptions of Plumb and Ko (1992) fail, since at the vortex edge the quasi-horizontal mixing on an isentrope is not fast enough to equilibrate mixing ratio variations. In the inner vortex region the time scale for vertical advection is of the same size as horizontal transport across the edge. Furthermore, the vortex undergoes dramatic changes over the seasons (it forms, breaks up and resolves). 

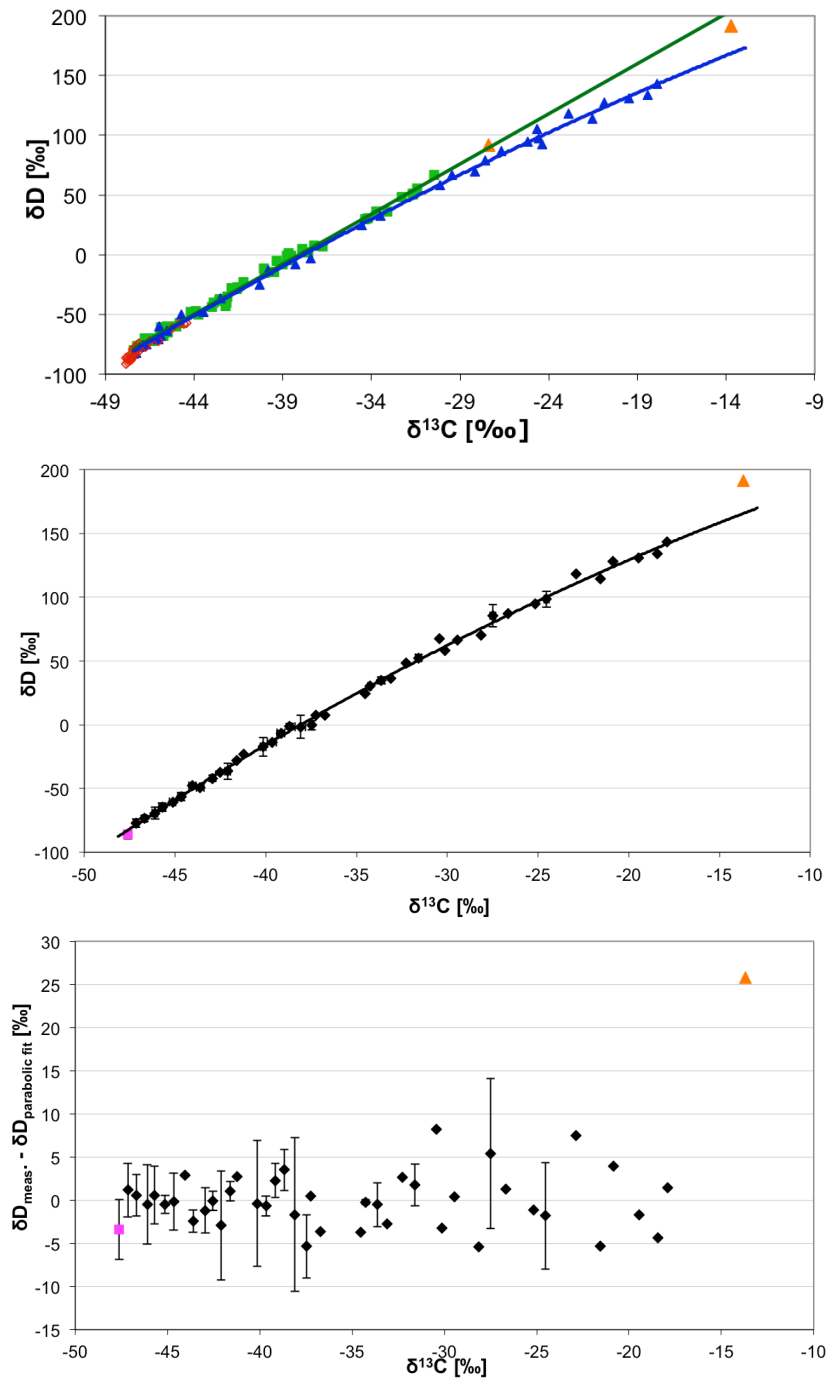

Fig. 3. Isotope-isotope correlation (a) for tropical (red) mid-latitude (green) and polar (blue) samples, exceptional samples from KIR03-03 $\triangle \triangle$ ) in orange. Mid-latitude samples follow a linear fit, whereas polar samples follow a parabolic fit. The parabolic shape dominates in the fit to all data (b). Here, the data was binned in $0.5 \% \circ \delta^{13} \mathrm{C}$ intervals to reduce the statistical weight of the more abundant higher mixing ratio (lower $\delta$-values) samples. The residuals between parabolic fit and data (c), excluding the highest enrichment point, show no systematic structure. The error bars represent typical variations in a $0.5 \% \circ \delta^{13} \mathrm{C}$ bin.

Secondly, there is comparably large scatter for $\delta \mathrm{D}$ at high methane mixing ratios, i.e. near the tropopause, where the $\delta \mathrm{D}$ - mixing ratio correlations are slightly shifted between individual flights. This point will be further investigated below.

\subsubsection{Isotope - isotope correlations}

Figure 3 shows the isotope - isotope correlation between $\delta \mathrm{D}$ and $\delta^{13} \mathrm{C}$. In such a plot, air that is a result of mixing between two air parcels is found on a straight line connect- ing these two parcels. Such a linear mixing correlation in fact fits the mid-latitude data points well. This means that the spatial and temporal distribution of $\mathrm{CH}_{4}$ and its isotopic composition can be explained by mixing of tropospheric air with a representative strongly processed reservoir in the upper stratosphere. Interestingly, the vortex samples significantly deviate from this straight (mid-latitudinal) correlation. For a global fit, the data was binned in $0.5 \% \circ \delta^{13} \mathrm{C}$ intervals to reduce the statistical weight of the more abundant higher mixing ratio (lower $\delta$-values) samples. When the point with highest isotope enrichment (sample KIR-03-03/12) is disregarded, a parabolic fit of the form

$$
\begin{aligned}
\delta \mathrm{D} & =-0.0557 \cdot\left(\delta^{13} \mathrm{C}\right)^{2}+3.9017 \cdot \delta^{13} \mathrm{C}+229.39 \\
r^{2} & =0.9978
\end{aligned}
$$

fits the data well without systematic structure in the residuals (Fig. 3c). The most interesting feature of the fit in Fig. 3b is its monotonically decreasing slope. This implies a decrease of $\mathrm{D}$ fractionation compared to ${ }^{13} \mathrm{C}$ fractionation at higher total enrichments (see below). Pure Rayleigh fractionation processes would actually show a slightly increasing slope, which is due to the non-linearity of the Rayleigh fractionation equation, so other process must contribute. Given the large differences in the fractionation constants associated with the three chemical sink reactions (see below), the overall monotonous decrease can only be caused by a continuously decreasing strength of the $\mathrm{OH}$ sink and the related increase of the $\mathrm{O}\left({ }^{1} \mathrm{D}\right)$ and $\mathrm{Cl}$ strength (and to a minor degree shifting from $\mathrm{Cl}$ to $\left.\mathrm{O}\left({ }^{1} \mathrm{D}\right)\right)$.

The two vortex samples that fall below and above the mesospheric enclosure in flight KIR-03-03 deviate from this general description. According to Engel et al. (2006), sample KIR-03-03/8, has typical characteristics of upper stratospheric air from the mid-latitudes and indeed it accurately falls onto the mid-latitudinal mixing line and marks its most enriched end-point (Fig. 3a). The second sample, KIR-03$03 / 12$, is more difficult to interpret, as it is completely isolated from the other samples in the isotope:isotope plane. It will be further discussed below.

\subsection{Comparison to previous datasets}

\subsection{1 $\quad \delta^{13} \mathrm{C}$ comparison}

In the published literature, there is a clear difference between the $\delta^{13} \mathrm{C}$ data from Sugawara et al. (1997) (balloon) and Rice et al. (2003) (ER-2 flights). The data from Sugawara et al. (1997) are approximately $0.5 \%$ more depleted, which has been attributed either to the different location/time period of sampling or to lab-specific calibration procedures (Rice et al., 2001). When compared to our data, the Rice et al. (2003) data (1996-2000) fall in the range of the Arctic aircraft and balloon samples from 2003. At the same time, the KIR-9201 profile agrees well with the Sugawara et al. (1997) data from the 1994 balloon profile. Thus, the new comprehensive 
measurements indicate that the difference between the Sugawara et al. (1997) and Rice et al. (2003) data is likely not an analytical artefact and probably due to the temporal trends.

\subsection{2 $\delta \mathrm{D}$ comparison}

In comparison to Rice et al. (2003) the $\delta \mathrm{D}$ values presented here are about $10 \%$ heavier. The difference appears to decrease towards lower mixing ratios and may disappear at $700 \mathrm{ppb}$. Several processes may contribute to the discrepancy. A fractionation in the sampling procedure is unlikely for our analyses, as samples from different sampling devices agree well. Given the fact that both $\delta \mathrm{D}$ datasets cover large regions of the stratosphere, it is unlikely that the observed difference indicates a real atmospheric difference. Most likely the deviation in $\delta \mathrm{D}$ originates from different, labspecific calibration scales. This typically leads to systematic deviations. Ideally, these deviations are constant, but they can also increase or decrease with mixing ratio, as observed. Because of this non-constant deviation, the ER-2 data discussed by Rice et al. (2003) and McCarthy et al. (2003) show a more pronounced relative vertical increase of $\delta \mathrm{D}$ in the stratosphere, i.e. a generally higher slope of $\delta \mathrm{D}(c)$ relation, and consequently slightly higher $\mathrm{KIE}^{\mathrm{D}}$-values are reported by Rice et al. (2003) and McCarthy et al. (2003).

\section{Chemical and physical effects on the isotopic composition}

\subsection{Chemical isotope fractionation in the removal reactions}

In the stratosphere methane is oxidised by $\mathrm{OH}, \mathrm{O}\left({ }^{1} \mathrm{D}\right)$ and $\mathrm{Cl}$. Due to slightly different reaction rate coefficients for the different isotopologues, chemical removal by these reactions leads to a shift in the isotope ratio of the residual material. Neglecting other effects, this can be described by the wellknown Rayleigh fractionation equation (Kaiser et al., 2002b).

$\ln \left(\frac{\delta+1}{\delta_{0}+1}\right)=\left(\frac{1}{\mathrm{KIE}}-1\right) \ln \left(\frac{c}{c_{0}}\right)$

$\delta$ and $\delta_{0}$ are the initial and final $\delta$-values and $c_{0}$ and $c$ are the initial and final mixing ratios. KIE is the kinetic isotope effect, defined as the ratio of the reaction rate constants for the light $(k)$ and heavy $\left(k^{\prime}\right)$ isotopologue

$\mathrm{KIE}=\frac{k}{k^{\prime}}$

A normal kinetic isotope effect is characterised by $k>k^{\prime}$. In case of a constant KIE, it can be determined from the slope of a Rayleigh fractionation plot where $(\delta+1)$ is plotted versus $\ln \left(\frac{c}{c_{0}}\right)$ (Eq. 2). The corresponding fractionation constant $\varepsilon$ is defined as

$\varepsilon=\mathrm{KIE}-1$
As for $\delta$-values, the numerical values of $\varepsilon$ are usually stated in per mille. Note that in many publications $\varepsilon$ is defined as $\alpha-1$ (where $\alpha=k^{\prime} / k=(\mathrm{KIE})^{-1}$ ). The same symbol $\varepsilon$ is used in both cases, which are not equivalent.

Saueressig et al. (2001) determined the KIE values and their temperature dependence for the reactions of $\mathrm{OH}, \mathrm{O}\left({ }^{1} \mathrm{D}\right)$ and $\mathrm{Cl}$ with the three major isotopologues ${ }^{12} \mathrm{CH}_{4},{ }^{13} \mathrm{CH}_{4}$, ${ }^{12} \mathrm{CH}_{3} \mathrm{D}$ (Table 1). Rice et al. (2003) showed that for three simultaneous sink reactions the combined effective KIE can be written as the sum of the KIEs weighted by the respective sink fractions $a_{\mathrm{Y}}$ of methane oxidised by $\mathrm{Y}\left(\mathrm{Y}=\mathrm{OH}, \mathrm{O}\left({ }^{1} \mathrm{D}\right)\right.$, $\mathrm{Cl})$.

$$
\begin{aligned}
& \mathrm{KIE}_{\text {eff }}^{13}=a_{\mathrm{OH}} \mathrm{KIE}_{\mathrm{OH}}^{13} \mathrm{C}+a_{\mathrm{O}^{1} \mathrm{D}} \mathrm{KIE}_{\mathrm{O}^{1} \mathrm{D}}^{13}+a_{\mathrm{Cl}} \mathrm{KIE}_{\mathrm{Cl}}^{13} \mathrm{C} \\
& \mathrm{KIE}_{\text {eff }}^{\mathrm{D}}=a_{\mathrm{OH}} \mathrm{KIE}_{\mathrm{OH}}^{\mathrm{D}}+a_{\mathrm{O}^{1} \mathrm{D}} \mathrm{KIE}_{\mathrm{O}^{1} \mathrm{D}}^{\mathrm{D}}+a_{\mathrm{Cl}} \mathrm{KIE}_{\mathrm{Cl}}^{\mathrm{D}} \\
& 1=a_{\mathrm{OH}}+a_{\mathrm{O}^{1} \mathrm{D}}+a_{\mathrm{Cl}}
\end{aligned}
$$

Equation (5) is a set of 3 linear equations with 3 unknowns and can also be formulated as vector equation

$$
\left(\begin{array}{c}
\mathrm{KIE}_{\text {eff }}^{13} \mathrm{C} \\
\mathrm{KIE}_{\mathrm{eff}}^{\mathrm{D}} \\
1
\end{array}\right)=\left(\begin{array}{ccc}
\mathrm{KIE}_{\mathrm{OH}}^{13} \mathrm{C} & \mathrm{KIE}_{\mathrm{O}^{1} \mathrm{D}}^{13} & \mathrm{KIE}_{\mathrm{Cl}}^{13} \mathrm{C} \\
\mathrm{KIE}_{\mathrm{OH}}^{\mathrm{D}} & \mathrm{KIE}_{\mathrm{O}^{1} \mathrm{D}}^{\mathrm{D}} & \mathrm{KIE}_{\mathrm{Cl}}^{\mathrm{D}} \\
1 & 1 & 1
\end{array}\right)\left(\begin{array}{c}
a_{\mathrm{OH}} \\
a_{\mathrm{O}^{1} \mathrm{D}} \\
a_{\mathrm{Cl}}
\end{array}\right)
$$

In this framework it is possible to formally derive the relative sink fractions $\left(a_{\mathrm{OH}}, a_{\mathrm{O}^{1} \mathrm{D}}\right.$ and $\left.a_{\mathrm{Cl}}\right)$ from the measurement of both $\mathrm{KIE}_{\text {eff }}$ values, if $\mathrm{KIE}_{\text {eff }}$ is accessible from measurements in the stratosphere.

\subsection{The effect of mixing}

The isotopic composition in the stratosphere is not only determined by the KIE in the chemical removal reactions, but also by transport and mixing processes. Mixing always acts to reduce gradients, and therefore the actually observed $a p$ parent $\mathrm{KIE}_{\text {app }}$ in the stratosphere is always smaller than the average effective $\mathrm{KIE}_{\text {eff }}$ from the formal sink partitioning derived above (see e.g. Rahn et al., 1998; Kaiser et al., 2002a). The effect of mixing can be quantified by introducing two dynamical parameters $f^{13} \mathrm{C}$ and $f^{\mathrm{D}}$.

$$
f^{13} \mathrm{C}:=\frac{\mathrm{KIE}_{\text {app }}^{13}-1}{\operatorname{KIE}_{\text {eff }}^{13}-1}=\frac{\varepsilon_{\text {app }}^{13} \mathrm{C}}{\varepsilon_{\text {eff }}^{13}} ; \quad f^{\mathrm{D}}:=\frac{\mathrm{KIE}_{\text {app }}^{\mathrm{D}}-1}{\mathrm{KIE}_{\text {eff }}^{\mathrm{D}}-1}=\frac{\varepsilon_{\text {app }}^{\mathrm{D}}}{\varepsilon_{\text {eff }}^{\mathrm{D}}}
$$

Thus, $f=1$ characterises an undisturbed Rayleigh fractionation process, whereas mixing generally leads to lower values of $f$, i.e. $\mathrm{KIE}_{\mathrm{app}}<\mathrm{KIE}_{\text {eff. }} f^{13} \mathrm{C}$ and $f^{\mathrm{D}}$ can be included in the Eq. (6) to derive the sink partitioning as follows:

$$
\left(\begin{array}{c}
a_{\mathrm{OH}} \\
a_{\mathrm{O}^{1} \mathrm{D}} \\
a_{\mathrm{Cl}}
\end{array}\right)=\left(\begin{array}{ccc}
\mathrm{KIE}_{\mathrm{OH}}^{13} \mathrm{C} & \mathrm{KIE}_{\mathrm{O}^{1} \mathrm{D}}^{13} & \mathrm{KIE}_{\mathrm{Cl}}^{13} \mathrm{C} \\
\mathrm{KIE}_{\mathrm{OH}}^{\mathrm{D}} & \mathrm{KIE}_{\mathrm{O}^{1} \mathrm{D}}^{\mathrm{D}} & \mathrm{KIE}_{\mathrm{Cl}}^{\mathrm{D}} \\
1 & 1 & 1
\end{array}\right)^{-1}\left(\begin{array}{c}
1+\frac{\mathrm{KIE}_{\text {eff }}^{13} \mathrm{C}-1}{f^{13} \mathrm{C}} \\
1+\frac{\mathrm{KIE}_{\text {eff }}^{\mathrm{D}}-1}{f^{\mathrm{D}}} \\
1
\end{array}\right)
$$


Table 3. Mean KIE per flight, in brackets error on last digits. Additionally the column " $c_{\text {min }}$ " shows the minimal mixing ratio in a sample set used to derive the corresponding mean KIE.

\begin{tabular}{|c|c|c|c|c|c|c|c|c|}
\hline Sample set & $\mathrm{KIE}^{13} \mathrm{C}$ & $r^{2}$ & $\begin{array}{l}\text { Excluded } \\
\text { samples }\end{array}$ & $\begin{array}{l}c_{\min } \\
\mathrm{ppb}\end{array}$ & $\mathrm{KIE}^{\mathrm{D}}$ & $r^{2}$ & $\begin{array}{l}\text { Excluded } \\
\text { samples }\end{array}$ & $\begin{array}{l}c_{\min } \\
\mathrm{ppb}\end{array}$ \\
\hline KIR-92-01 & $1.0162(3)$ & 0.996 & & 265 & $1.142(1)$ & 0.999 & 8,9 & 335 \\
\hline KIR-92-02 & $1.0157(3)$ & 0.997 & & 272 & $1.129(2)$ & 0.999 & & 272 \\
\hline KIR-92-03 & $1.0144(3)$ & 0.996 & & 397 & $1.128(3)$ & 0.997 & & 397 \\
\hline KIR-00-01 & $1.0170(2)$ & 0.999 & & 248 & & & & \\
\hline KIR-03-03 & $1.0168(3)$ & 0.998 & 1,12 & 271 & $1.133(5)$ & 0.991 & 12 & 271 \\
\hline average (vortex) & $1.0160(10)$ & & & & $1.133(6)$ & & & \\
\hline KIR-03-06 & $1.0168(5)$ & 0.991 & & 652 & $1.147(4)$ & 0.993 & & 652 \\
\hline KIR-95-03 & $1.0148(4)$ & 0.995 & & 835 & $1.150(3)$ & 0.998 & & 835 \\
\hline average (non-vortex) & $1.0158(14)$ & & & & $1.146(0.5)$ & & & \\
\hline average (all polar) & $1.0159(9)$ & & & & $1.138(8)$ & & & \\
\hline ASA-93-09 & $1.0153(5)$ & 0.989 & 7 & 831 & $1.160(6)$ & 0.984 & & 613 \\
\hline GAP-99-06 & $1.0165(4)$ & 0.993 & & 631 & $1.153(3)$ & 0.997 & & 631 \\
\hline ASA-01-10 & $1.0153(2)$ & 0.998 & & 957 & & & & \\
\hline ASA-02-09 & $1.0151(5)$ & 0.989 & & 897 & $1.140(21)$ & 0.936 & & 897 \\
\hline average (mid) & $1.0156(6)$ & & & & $1.151(10)$ & & & \\
\hline HYD-87-03 & $1.0119(8)$ & 0.987 & & 1233 & $1.123(9)$ & 0.988 & & 1233 \\
\hline HYD-99-04 & $1.0135(10)$ & 0.964 & 15 & 1486 & $1.122(12)$ & 0.947 & & 1486 \\
\hline average (subtropics) & $1.0127(11)$ & & & & $1.122(1)$ & & & \\
\hline average (all latitudes) & $1.0147(2)$ & & & & $1.137(14)$ & & & \\
\hline
\end{tabular}

A consequence of the steady-state in the global mixing scheme is that the net vertical trace gas fluxes are purely diffusive (Plumb, 1996). For this specific case of pure diffusive mixing, a simplified discussion on the resulting isotope profile was already presented in Kaye (1987) (see also Erikson, 1965). In this idealised 1-D-diffusive steady-state model $f$-values between 0.5 and 1 are theoretically possible (independent of molecule and/or isotope), where $f=0.5$ characterises the so-called diffusion-limited case, which describes the situation expected for the stratosphere (Rahn et al., 1998; Kaiser et al., 2002a). Thus, the apparent $\mathrm{KIE}_{\text {app }}$ is only half of the expected $\mathrm{KIE}_{\text {eff. }}$. It will be shown below that in general this 1-D-diffusive model (thus $f=0.5$ ) already predicts the stratospheric fractionation surprisingly well.

An additional effect in the real stratosphere occurs by mixing across transport barriers, where air masses (or parts of them) with distinct characteristics are irreversibly mixed. Also in this case, the observed $\mathrm{KIE}_{\text {app }}$ will always be lower than $\mathrm{KIE}_{\text {eff }}$ (i.e. $f<1$ ) (Kaiser et al., 2002a). If the $\mathrm{KIE}_{\text {app }}$ values of the mixing air masses themselves are already at the diffusion-limited extreme individually $(f=0.5)$, then the additional effect of mixing across a transport barrier (e.g. the polar vortex) will be to reduce $f$ further to $f<0.5$.

\section{Mean fractionation factor}

For each individual balloon profile, a mean KIE can be determined from a linear fit to the data in a double-logarithmic plot such as Fig. 4 according to Eq. (2). The results of those mean KIE values are shown in Table 3. The corresponding fractionation factors vary for the individual flights over the range $12-17 \%$ or $\varepsilon^{13} \mathrm{C}$ and $122-160 \%$ for $\varepsilon^{\mathrm{D}}$.

In general the fits are of very good quality and give high accuracy KIE values with the following exceptions. The HYD-87-03 profile basically consists of only two groups of points. For HYD-99-04 half of the profile shows nearly constant (tropospheric) values, which effectively reduces the number of useful samples. Additionally, both HYD profiles occupy only a small c-interval in the $\delta(c)$ relations. Also for $\mathrm{KIE}^{\mathrm{D}}$ (ASA-02-09) the regression coefficient is lower, likely due to the limited number of samples analysed for $\delta \mathrm{D}$.

Previously published mean KIE values are listed in Table 4 for comparison. The $\mathrm{KIE}^{13} \mathrm{C}$ derived by Sugawara et al. (1997), the only previously published result from a stratospheric balloon flight, is similar to the subtropical (HYD-9904) result from this study. The overall average of Rice et al. (2003) is in very good agreement with the mid-latitudinal 

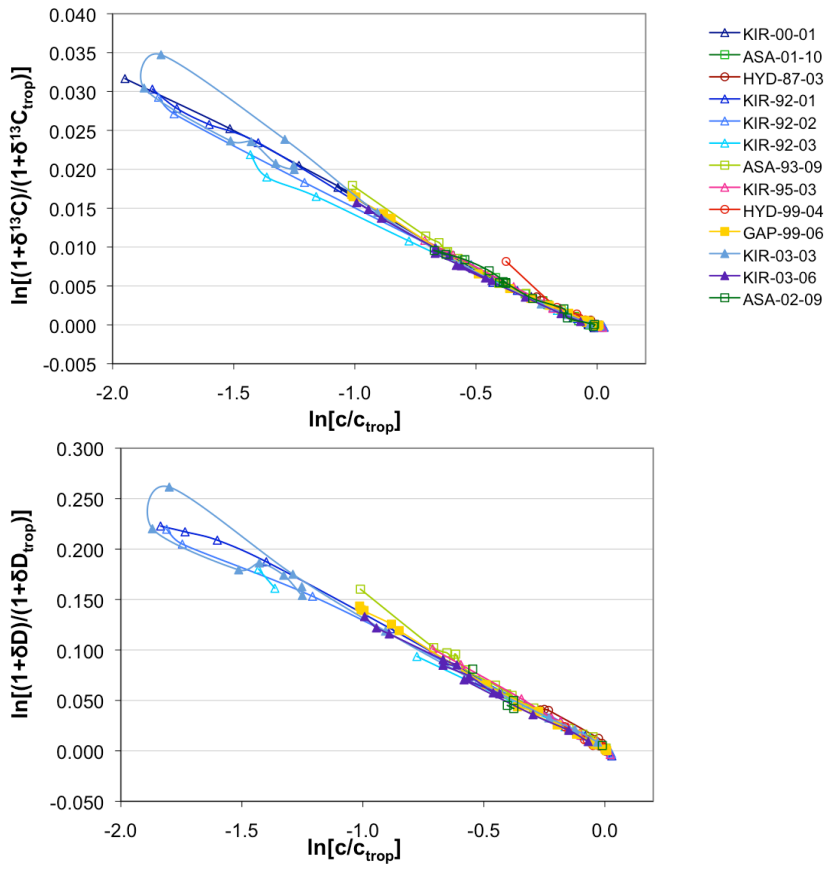

Fig. 4. Rayleigh plots used for deriving the mean fractionation factors for $\delta^{13} \mathrm{C}$ and $\delta \mathrm{D}$. Some exceptional points have been neglected for the fitting procedure. The lines in the graphs connect the points of each flight according to the sampling altitude. Regression lines are left out, since the principal linear dependence is obvious.

average of this work. Rice et al. (2003) observed an apparent increase of the $\mathrm{KIE}_{\mathrm{app}}$ towards decreasing mixing ratios in the regions of higher mixing ratios. For our data, a slight curvature towards lower mixing ratios can be detected for $\delta^{13} \mathrm{C}$ (Fig. 4a). For $\delta \mathrm{D}$ (Fig. 4b), including the results of highly processed polar air from our high altitude polar balloon samples leads to slightly lower values for $\varepsilon^{\mathrm{D}}$ compared to Rice et al. (2003). The change of $\mathrm{KIE}_{\mathrm{app}}$ with mixing ratio will be discussed in detail in Sect. 6.2.

The samples reported in Brenninkmeijer et al. (1995, 1996) were collected in the southern hemispheric lower stratosphere $(10-12 \mathrm{~km})$ at mid and high latitudes. They cover only a small range in mixing ratio $(1620-1690 \mathrm{ppb})$. No comparable data set is available from this work. Nevertheless, similar KIEs are observed, if the new dataset is restricted to high mixing ratio samples only.

A long-term temporal trend in the KIE-values is not discernible from the data in Table 3. Nevertheless, one further factor needs to be corrected for, namely the correction of the bias introduced by the presence of the tropospheric temporal trends.

\subsection{Correction for tropospheric trends}

The evaluation of mean KIEs from each single profile as discussed so far relates the highest altitude sample, which has resided in the stratosphere for years, to the lowermost sam-
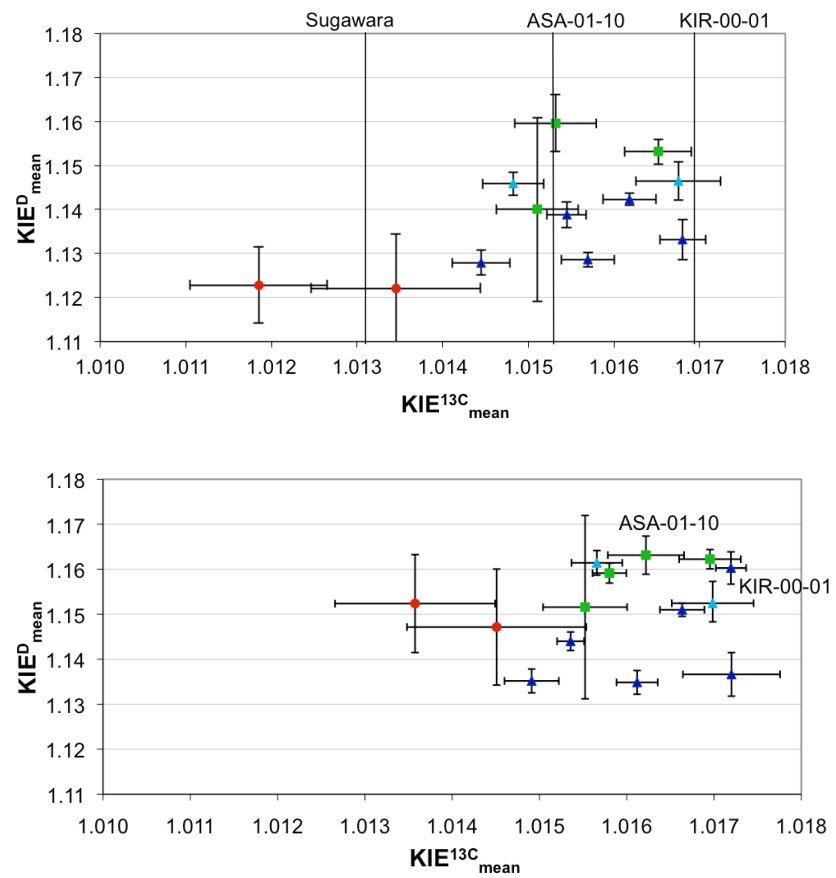

Fig. 5. Mean KIE determined before (upper panel) and after (lower panel) applying the correction for tropospheric trends. Errors result from fit uncertainty. Flights are grouped and colour-coded according to their cut-off bias (subtropical: red ๑; mid-latitudes: green $\square$; Arctic vortex: dark blue $\boldsymbol{\Delta}$ and Arctic non-vortex: light blue $\triangle)$ KIR-00-01 and ASA-01-10 in the bottom figure are based on pseudo- $\delta \mathrm{D}$ values calculated from the isotope:isotope correlation. In the top figure only the real $\mathrm{KIE}^{13} \mathrm{C}$ values are shown for those flights, indicated by vertical lines. Additionally, the only previous published balloon profile ( ${ }^{13} \mathrm{C}$ only) from Sugawara et al. (1997) is included for direct comparison to the other flights.

ple, which only recently entered the stratosphere or is still located in the upper troposphere. This method will only reflect the true chemical and dynamical stratospheric fractionation in the absence of tropospheric trends. If, however, tropospheric trends exist, then the higher altitude stratospheric samples are related to initial tropospheric values that do not reflect the conditions at the time the sample entered the stratosphere. The deviation is the bigger the larger the tropospheric trends are and the longer the sample of interest already resides in the stratosphere. A correction for the tropospheric trends using the concept of stratospheric "mean age" Kida (1983) is presented in Appendix A.

The mean age corrected fractionation constants are listed in Table 5 together with the absolute and relative change from the uncorrected values (Table 3). In general the mean age correction leads to higher KIE-values, and the effect increases towards lower latitudes. In tendency, it amplifies the $\mathrm{KIE}^{\mathrm{D}}$ signal relative to $\mathrm{KIE}^{13} \mathrm{C}$. This is related to the relative size of the tropospheric $\delta$-trend, which for $\delta^{13} \mathrm{C}$ is small. 
Table 4. Previously published mean KIE values.

\begin{tabular}{|c|c|c|c|c|c|c|}
\hline Location & & max. altitude & year-month & $\mathrm{KIE}^{13} \mathrm{C}$ & $\mathrm{KIE}^{\mathrm{D}}$ & Reference \\
\hline Antarctica supply & Aircraft & 12 & 1993-06 & 1.012 & & Brenninkmeijer et al. (1995) \\
\hline Antarctica supply & Aircraft & 12 & $1993-10$ & 1.010 & & Brenninkmeijer et al. (1996) \\
\hline Japan & Balloon & 34.7 & 1994-08 & $1.0131(6)$ & & Sugawara et al. (1997) \\
\hline STRAT, POLARIS, SOLVE & Aircraft & 21 & $1996-09$ to $2000-03$ & $1.0154(8)$ & $1.153(10)$ & Rice et al. (2003), overall average ( $2 \sigma)$ \\
\hline
\end{tabular}

Table 5. Mean fractionation constants $\varepsilon^{13} \mathrm{C}$ and $\varepsilon^{\mathrm{D}}$, corrected for tropospheric trends. The absolute differences in $\% \circ$ and the relative change in $\%$ to the uncorrected fractionation constants are stated in the right columns.

\begin{tabular}{|c|c|c|c|c|c|c|c|c|}
\hline \multirow[t]{2}{*}{ Set } & \multirow{2}{*}{$\begin{array}{l}c_{\min } \\
\mathrm{ppb}\end{array}$} & \multirow{2}{*}{$\begin{array}{l}\varepsilon^{13} \mathrm{C} \\
\% o\end{array}$} & \multirow{2}{*}{$\begin{array}{l}c_{\min } \\
\mathrm{ppb}\end{array}$} & \multirow{2}{*}{$\begin{array}{l}\varepsilon^{\mathrm{D}} \\
\% o\end{array}$} & \multicolumn{2}{|c|}{ changes abs. } & \multicolumn{2}{|c|}{ changes rel. } \\
\hline & & & & & $\Delta[\% o]$ & $\Delta[\% o]$ & {$[\%]$} & {$[\%]$} \\
\hline KIR-00-01 & 248 & 17.2 & $(248)^{*}$ & $(160)^{*}$ & 0.2 & & 1.4 & \\
\hline KIR-92-01 & 265 & 16.6 & 335 & 151 & 0.5 & 9 & 2.8 & 6.1 \\
\hline KIR-92-02 & 272 & 16.1 & 272 & 135 & 0.4 & 6 & 2.7 & 4.9 \\
\hline KIR-92-03 & 397 & 14.9 & 397 & 135 & 0.5 & 7 & 3.2 & 5.7 \\
\hline KIR-03-03 & 271 & 17.2 & 271 & 137 & 0.4 & 3 & 2.4 & 2.6 \\
\hline KIR-03-06 & 652 & 17.0 & 652 & 152 & 0.2 & 6 & 1.4 & 4.1 \\
\hline ASA-93-09 & 831 & 16.2 & 613 & 163 & 0.9 & 4 & 5.9 & 2.2 \\
\hline KIR-95-03 & 835 & 15.7 & 835 & 161 & 0.8 & 16 & 5.6 & 10.7 \\
\hline GAP-99-06 & 631 & 17.0 & 631 & 162 & 0.4 & 9 & 2.6 & 5.9 \\
\hline ASA-01-10 & 957 & 15.8 & $(957)^{*}$ & $(159)^{*}$ & 0.5 & & 3.3 & \\
\hline ASA-02-09 & 897 & 15.5 & 897 & 152 & 0.4 & 12 & 2.8 & 8.3 \\
\hline HYD-87-03 & 1233 & 13.6 & 1233 & 152 & 1.7 & 30 & 14.6 & 24.0 \\
\hline HYD-99-04 & 1486 & 14.5 & 1486 & 147 & 1.1 & 25 & 7.9 & 20.5 \\
\hline
\end{tabular}

${ }^{*}$ Using pseudo data, i.e. calculated $\delta \mathrm{D}$-values according to the $\delta \mathrm{D}-\delta^{13} \mathrm{C}$ correlation (1).

Figure 5 shows the uncorrected (a) and the mean age corrected (b) mean KIE values in direct comparison. After applying the correction the mean KIEs are grouped more closely together in the KIE - KIE plane, but the remaining scatter is still about $3 \%$ for $\mathrm{KIE}^{13} \mathrm{C}$ and $\sim 30 \%$ for $\mathrm{KIE}^{\mathrm{D}}$. The largest systematic feature in Fig. $5 \mathrm{~b}$ is the rather low $\mathrm{KIE}^{13} \mathrm{C}$ for the subtropical flights. In addition, $\mathrm{KIE}^{\mathrm{D}}$ is lower for the vortex flights than for the mid latitude flights. These variations will be examined in the following sections. In the remainder of this paper only the mean age corrected fractionation constants are discussed.

\subsection{Latitudinal mixing ratio cut-off bias and non- constant apparent KIE}

An additional effect can cause apparent differences between measurements at different latitudes. If the apparent KIE is not constant over the entire range of mixing ratios, the value of the minimum mixing ratio $c_{\min }$ of each sample profile affects the mean KIEs at different latitudes. Due to the strong latitudinal mixing ratio gradient in the stratosphere, the minimum mixing ratio $c_{\min }$ that is sampled on each balloon flight differs for the different regions. At altitudes of about
$30 \mathrm{~km}$ (typical maximum altitude of the balloon flights) $c_{\text {min }}$ is around $1200 \mathrm{ppb}$ for the subtropics, $650 \mathrm{ppb}-900 \mathrm{ppb}$ for mid latitudes and polar regions without vortex influence, and $\sim 300 \mathrm{ppb}$ for vortex flights. The difference in $c_{\text {min }}$ can lead to a bias when comparing profiles from different regions if KIE increases with decreasing mixing ratio. In this case, the mean KIEs from the subtropical flights would be higher simply because only air with relatively high $\mathrm{CH}_{4}$ mixing ratios was sampled. Figure 6 shows that indeed $\mathrm{KIE}^{13} \mathrm{C}$ decreases with decreasing $c_{\min }$. We call this effect "latitudinal cut-off" bias.

In order to assess whether a latitudinal cut-off bias occurs in our set of samples, Fig. 7 shows how the KIE changes when successively the highest points of each individual profile are truncated ("bottom-up" profiles). Conversely, each point in these figures presents the KIE calculated for each individual balloon profile when only the points up to the designated altitude (x-axis) are included. For $\mathrm{KIE}^{13} \mathrm{C}$, it is evident that in particular for the vortex profiles, the value of $\mathrm{KIE}^{13} \mathrm{C}$ increases when successively lower mixing ratios are included in the evaluation of $\mathrm{KIE}^{13} \mathrm{C}$. For the same mixing ratio range, $\mathrm{KIE}^{13} \mathrm{C}$ values for the subtropics are similar than 


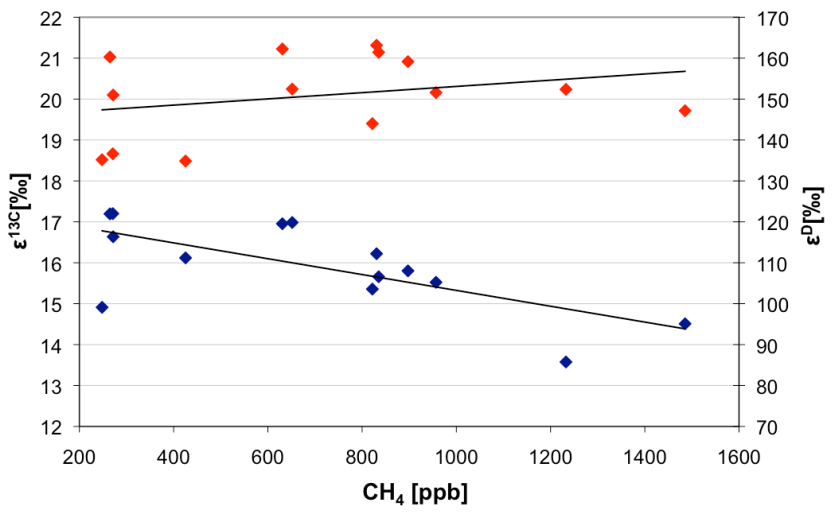

Fig. 6. Dependence of mean fractionation factors of each flight $\left(\varepsilon^{13} \mathrm{C}\right.$ in blue, $\varepsilon^{\mathrm{D}}$ in red) on the corresponding lowest mixing ratio $c_{\text {min }}$ observed. Fractionation factors are taken from Table 5 and include the correction for the tropospheric temporal trends.

those observed for mid and high latitudes. Thus, the fact that the tropical $\mathrm{KIE}^{13} \mathrm{C}$ values stand out low in Fig. 5b is mainly due to the latitudinal cut-off bias. There is even a tendency for the subtropical and mid latitude KIE's to be slightly higher than the vortex profiles in Fig. 7a.

Except for a large scatter in the high mixing ratio regime, where the inverse mixing ratio spans only a small interval and high extrapolation errors are expected, no systematic cut-off bias is observed for $\mathrm{KIE}^{\mathrm{D}}$ (Fig. 7b). The values in this figure support the observation from Fig. $5 \mathrm{~b}$ that the $\mathrm{KIE}^{\mathrm{D}}$ values for vortex air are generally slightly lower than for mid latitude air.

\section{$7 \quad$ Limitations of global mean sink partitioning}

In this section it will be investigated whether/how the derived mean KIE can be used to derive the mean relative strengths of the three stratospheric sink reactions. It is already clear from Eq. (8) that the results will depend on $f^{13} \mathrm{C}$ and $f^{\mathrm{D}}$, but we will show that there are even more limitations.

\subsection{Sink partitioning - results from previous models}

Two extended 2-D-model studies on the isotopic composition of stratospheric methane have been published. Bergamaschi et al. (1996), updated in Saueressig et al. (2001), used a photochemical 2-D-model to predict the distribution of $\mathrm{OH}$, $\mathrm{O}\left({ }^{1} \mathrm{D}\right)$ and $\mathrm{Cl}$ in the stratosphere. The model is able to reproduce the $\delta^{13} \mathrm{C}(c)$ fractionation profile from Sugawara et al. (1997). According to this model, in the middle and upper stratosphere $(p<10 \mathrm{hPa}) \mathrm{Cl}$ accounts for $\sim 20 \%$ of the $\mathrm{CH}_{4}$ sink strength at low and mid-latitudes and for $\sim 30 \%$ at high latitudes. $\mathrm{O}\left({ }^{1} \mathrm{D}\right)$ is estimated to cause $30 \%$ of the loss in the tropics and mid-latitudes (Fig. 5 in Bergamaschi
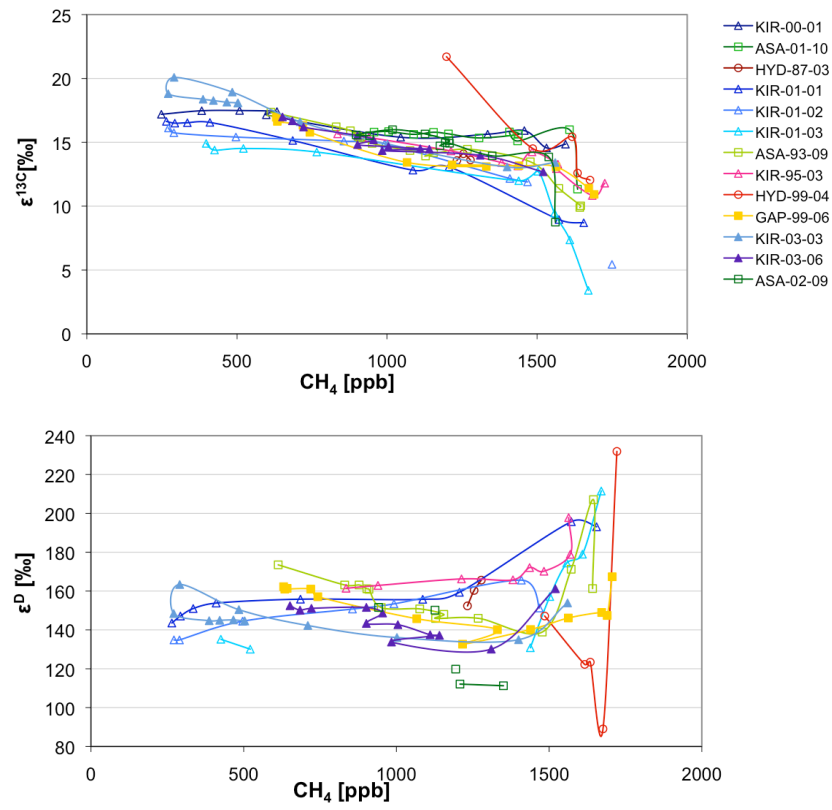

Fig. 7. The bottom-up profiles show the increase in $\varepsilon^{13} \mathrm{C}$ with decreasing $c_{\min }$, which illustrates the decreasing importance of $\mathrm{OH}$ with increasing altitude (decreasing mixing ratio) and reduction of $\delta \mathrm{D}$ relative to $\delta^{13} \mathrm{C}$ in the vortex. Some data points that include only lower stratospheric samples have been left out in the graphs, since they reflect tropospheric variations. The last data point (on the left side) of each line corresponds to the $\mathrm{KIE}_{\text {mean }}$ results of Table 5, but as exceptional samples have not been excluded here, they can slightly differ from the values given there. Typically the topmost sample has the lowest methane mixing ratio in a profile and therefore defines $c_{\min }$. The major exception is KIR-03-03 (light blue), which has a minimum in the vertical mixing ratio profile, so that instead of $c_{\min }$ the mixing ratio of the topmost sample characterises the related mean fractionation factor.

et al., 1996). The relative global mean sink strengths and the corresponding effective KIEs for these model results are for the year 1993 (C. Brühl, MPI für Chemie, Germany, personal communication, 2003):

$\left(a_{\mathrm{OH}}^{\mathrm{G}}, a_{\mathrm{O}^{1} \mathrm{D}}^{\mathrm{G}}, a_{\mathrm{Cl}}^{\mathrm{G}}\right)=(0.41,0.33,0.26)$

The second modelling study from McCarthy et al. (2003) yields similar numbers for the sink partitioning. Using the available KIEs for the individual reactions (Table 1), this translates into effective KIEs of

$$
\begin{aligned}
& \mathrm{KIE}_{\text {eff }}^{13} \mathrm{C}=25.39 \\
& \mathrm{KIE}_{\text {eff }}^{\mathrm{D}}=328.6
\end{aligned}
$$

In an inverse approach, the model results from Eq. (9) can be used in Eq. (8) to calculate $f^{13} \mathrm{C}$ and $f^{\mathrm{D}}$ from the average KIE measurements (Table 5). To take the cut-off bias in the determination of mean KIEs into account, this was done 
Table 6. Global mean dynamical factors $f^{13} \mathrm{C}$ and $f^{\mathrm{D}}$ inferred from the modelled sink partitioning and the averaged mean fractionation constants $\varepsilon^{13} \mathrm{C}$ and $\varepsilon^{\mathrm{D}}$. The second column of values for a certain signature always gives the error.

\begin{tabular}{ll|rr|rr|rr|rr}
\hline & average & $\varepsilon^{13} \mathrm{C}$ & $\varepsilon^{\mathrm{D}}$ & \multicolumn{2}{|c}{$f^{13} \mathrm{C}$} & \multicolumn{2}{|c}{$f^{\mathrm{D}}$} \\
\hline 1 & subtropics & 14.0 & 0.7 & 150 & 4 & 0.553 & 0.026 & 0.456 & 0.011 \\
2 & mid-latitudes & 16.1 & 0.6 & 159 & 5 & 0.635 & 0.025 & 0.484 & 0.016 \\
3 & non-vortex & 16.3 & 0.9 & 157 & 6 & 0.643 & 0.037 & 0.478 & 0.019 \\
4 & vortex $_{5}$ & 16.2 & 1.0 & 144 & 10 & 0.639 & 0.038 & 0.437 & 0.031 \\
5 & polar $^{1}(3 / 4)$ & 16.3 & 0.9 & 147 & 11 & 0.640 & 0.035 & 0.447 & 0.033 \\
6 & Global $^{2}(1 / 2 / 5)$ & 15.5 & 1.2 & 152 & 6 & 0.610 & 0.049 & 0.462 & 0.019 \\
\hline
\end{tabular}

${ }^{1}$ Polar: average of rows 3 and $4{ }^{2}$ Global: average of rows 1,2 and 5.

separately for the different groups of flights and the results for $f^{13} \mathrm{C}$ and $f^{\mathrm{D}}$ are shown in Table 6.

It is obvious that $f^{13} \mathrm{C}$ and $f^{\mathrm{D}}$ differ significantly. Whereas all $f^{13} \mathrm{C}$ values exceed $0.5, f^{\mathrm{D}}$ is always below 0.5 . This is surprising since the effects of transport on the different isotope signatures are expected to be similar. (Note that small differences can occur since $\delta \mathrm{D}$ values are much larger than $\delta^{13} \mathrm{C}$ values.) However, in the formal sink partitioning approach based on Rice et al. (2003) (Eq. 8), the signal in $\delta \mathrm{D}$ appears strongly attenuated, when sink strengths from previous model studies are used. This is unexpected, since these models do agree with previous stratospheric observations. Given the good agreement of our dataset with previous measurements, we expect that the models would not strongly deviate from our data. Therefore, the low value of $f^{\mathrm{D}}$ and the strong difference from $f^{13} \mathrm{C}$ likely indicate other shortcomings. We will refer to this issue as $\mathrm{KIE}^{\mathrm{D}}$-discrimination. The $\mathrm{KIE}^{\mathrm{D}}$-discrimination increases towards higher latitudes, which is mainly caused by the latitudinal cut-off bias in the determination of the mean KIE. Additionally, the attenuation increases when deuterium depleted vortex air (compare the vortex branch of the $\delta \mathrm{D}: \delta^{13} \mathrm{C}$ relation, Sect. 4.2.1) is included in the sample set.

The observed $\mathrm{KIE}^{\mathrm{D}}$-discrimination and the fact that $f^{\mathrm{D}}<$ 0.5 point towards conceptual limitations of the sink partitioning approach using Eq. (8), which will be further examined in the following.

\subsection{Conceptual limitations of the partitioning approach and the origin of the $\mathrm{KIE}^{\mathrm{D}}$-discrimination}

The approach of deducing the sink partitioning from Eq. (8) is strictly applicable only for an idealized removal process where all three sink processes occur simultaneously in a well-mixed volume, i.e. $\mathrm{KIE}_{\text {eff }}$ is constant. However, the stratospheric sink processes do not occur simultaneously. The $\mathrm{OH}$ sink clearly dominates in the lower stratosphere and the other two sinks gain in importance with altitude. This partly sequential removal of $\mathrm{CH}_{4}$ is generally masked by the fact that diffusive mixing removes most of the resulting gradients in the apparent fractionation constants. This on the one hand precludes deriving details of the altitude distribution of the different sink processes in the stratosphere from isotope data, but also limits the use of the mean kinetic isotope effects in Eq. (8). This can be demonstrated in a simple calculation: the isotope fractionation of a typical tropospheric air sample $\left(c=1750 \mathrm{ppb}, \delta^{13} \mathrm{C}=-47.5 \% o, \delta \mathrm{D}=-81 \%\right.$ ) is calculated when three times $300 \mathrm{ppb}$ are subsequently removed by all three chemical sinks, but in different order. Table 7 lists the final $\delta$ values for all permutations of the sinks and clearly the final enrichments are very different. Although the perfect sequential removal in this idealized experiment exaggerates the issue, it illustrates that the order of removal is important for the final isotopic composition. In this idealized experiment we then use the final isotope composition to calculate again the apparent KIEs and the relative sink fractions (under the condition $f^{13} \mathrm{C}=f^{\mathrm{D}}$ ) for each scenario. Theoretically the sink partitioning should be calculated to $(1 / 3$; $1 / 3 ; 1 / 3)$, but this result is only retrieved for case 7 when the removal in fact occurs simultaneously.

The results in Table 7 illustrate that the mean KIE eff, and thus the sink partitioning derived using the mean KIE approach, is pathway dependent. A fairly realistic sink partitioning is only retrieved when the chemical loss due to $\mathrm{OH}$ occurs last (case 2 and 4). In all other cases, the $\mathrm{OH}$ fraction is severely underestimated, especially if loss by $\mathrm{OH}$ occurs first. The fraction $a_{\mathrm{O}^{1} \mathrm{D}}$ is always overestimated, especially if $\mathrm{O}\left({ }^{1} \mathrm{D}\right)$ is the last sink in the sequence. As a general rule, the last sink has the largest impact on the final $\delta$-value. This is not surprising, because the relative fraction of the $300 \mathrm{ppb}$ removed increases in the three successive steps (300/1750 in the first step, 300/1450 in the second step and 300/1150 in the third step). Since Rayleigh fractionation increases with the relative fraction removed, the last step has the largest impact.

In the stratosphere, the $\mathrm{OH}$ sink dominates at the lowest altitudes, which corresponds to case 1 or 6 in Table 7 . It is clear that $a_{\mathrm{OH}}$ is severely underestimated in both cases, and this can lead to the $\mathrm{KIE}^{\mathrm{D}}$ discrimination, as described 
Table 7. Final isotope fractionation (column 3 and 4) and effective kinetic isotope effect $\mathrm{KIE}_{\text {eff }}$ (column 5 and 6) fractionation for different

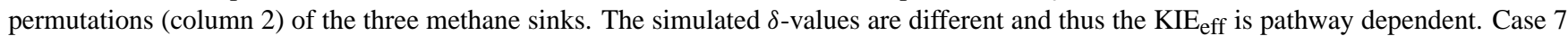
is a parallel removal by all three sink processes of equal strength, i.e. $\mathrm{KIE}_{\text {eff }}$ is constant along the fractionation pathway.

\begin{tabular}{llrrrrrrr}
\hline case & permutation & $\delta^{13} \mathrm{C}$ & $\delta \mathrm{D}$ & $\mathrm{KIE}_{\text {eff }}^{13} \mathrm{C}$ & $\mathrm{KIE}_{\text {eff }}^{\mathrm{D}}$ & $a_{\mathrm{OH}}$ & $a_{\mathrm{O}^{1} \mathrm{D}}$ & $a_{\mathrm{Cl}}$ \\
\hline 1 & $\mathrm{OH}-\mathrm{O}\left({ }^{1} \mathrm{D}\right)-\mathrm{Cl}$ & -24.3 & 93 & 1.035 & 1.327 & 0.18 & 0.44 & 0.39 \\
2 & $\mathrm{O}\left({ }^{1} \mathrm{D}\right)-\mathrm{Cl}-\mathrm{OH}$ & -28.9 & 95 & 1.028 & 1.330 & 0.35 & 0.35 & 0.30 \\
3 & $\mathrm{Cl}-\mathrm{OH}-\mathrm{O}\left({ }^{1} \mathrm{D}\right)$ & -30.7 & 65 & 1.026 & 1.264 & 0.24 & 0.52 & 0.24 \\
4 & $\mathrm{Cl}-\mathrm{O}\left({ }^{1} \mathrm{D}\right)-\mathrm{OH}$ & -31.2 & 80 & 1.025 & 1.297 & 0.35 & 0.41 & 0.24 \\
5 & $\mathrm{OH}-\mathrm{Cl}-\mathrm{O}\left({ }^{1} \mathrm{D}\right)$ & -28.0 & 70 & 1.030 & 1.275 & 0.17 & 0.53 & 0.29 \\
6 & $\mathrm{O}\left({ }^{1} \mathrm{D}\right)-\mathrm{OH}-\mathrm{Cl}$ & -24.6 & 103 & 1.035 & 1.349 & 0.25 & 0.36 & 0.39 \\
7 & $3 \times 1 / 3$ & -27.3 & 101 & 1.031 & 1.345 & 0.33 & 0.33 & 0.33 \\
\hline
\end{tabular}

above. These calculations indicate that the formal sink partitioning approach using observed values of $\mathrm{KIE}_{\mathrm{app}}$, assumptions about dynamical factors and effective KIEs expressed in Eq. (8) has conceptual deficiencies. For a realistic treatment it is necessary to use global models, where both chemistry and transport can be included explicitly.

\section{Global scale interpretation from the chemical and dynamical perspective}

Building on previous studies on the isotopic composition of $\mathrm{CH}_{4}$ and $\mathrm{N}_{2} \mathrm{O}$ in the stratosphere (e.g. Griffith et al., 2000; Röckmann et al., 2001; McCarthy et al., 2003; Rice et al., 2003; Park et al., 2004; Toyoda et al., 2001), Kaiser et al. (2006) presented a detailed interpretation of $\mathrm{N}_{2} \mathrm{O}$ isotope measurements from the majority of balloon samples presented in this study. Similar to $\mathrm{N}_{2} \mathrm{O}$, the chemical lifetime of $\mathrm{CH}_{4}$ throughout most of the stratosphere is longer than typical transport times and most of the $\mathrm{CH}_{4}$ is actually removed in the middle to upper stratosphere. One interesting question is whether the distribution of the long-lived gases in the stratosphere can therefore be fully described by an idealized "two end member mixing" where tropospheric air simply mixes with a representative upper stratospheric reservoir that has been strongly processed photochemically. Kaiser et al. (2006) demonstrated that such a two end member mixing produces a straight line in a plot of $\delta$ value versus inverse mixing ratio, a so-called "Keeling" plot. Samples with $\mathrm{N}_{2} \mathrm{O}$ mixing ratios above $200 \mathrm{ppb}$ actually show this behaviour. In the stratosphere, $200 \mathrm{ppb}$ of $\mathrm{N}_{2} \mathrm{O}$ roughly corresponds to $1200 \mathrm{ppb}$ of $\mathrm{CH}_{4}$ (Park et al., 2004). Figure 8 shows that the $\mathrm{CH}_{4}$ isotope data in this high mixing ratio regime ( $>1200 \mathrm{ppb}$ ) plot on a straight line on the Keeling plot. This subset of data contains all subtropical samples and most samples from the mid latitudes. However, for the samples from polar regions with much lower mixing ratios, the simple two end member mixing model actually deviates strongly from the observations.

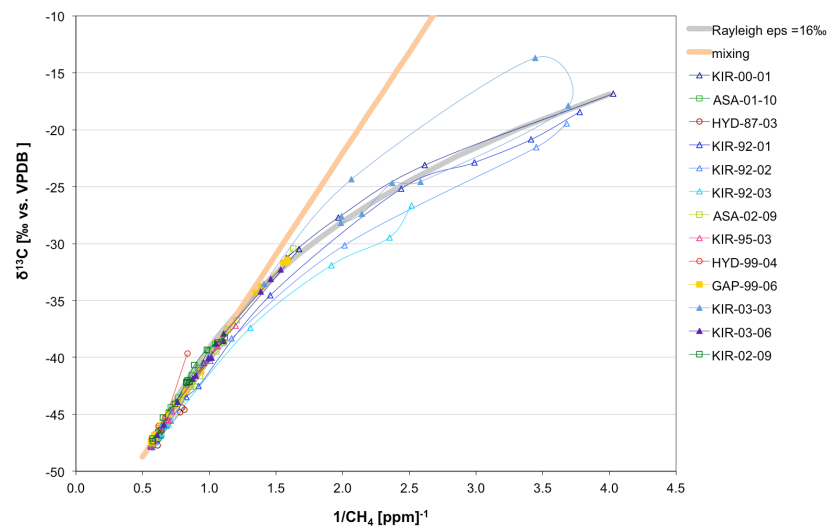

Fig. 8. $\delta^{13} \mathrm{C}$ plotted versus inverse mixing ratio. Mixing of two distinct air masses should result in a straight line in this plot (thick orange line), derived by a linear fit to all samples with mixing ratios below $1200 \mathrm{ppb}$, which is approximately equivalent to the high mixing ratio regime of $>200 \mathrm{ppb} \mathrm{N}_{2} \mathrm{O}$ (Kaiser et al., 2006). Also shown is a Rayleigh fractionation curve with $\varepsilon^{13} \mathrm{C}=16 \%$ (thick grey line), a value representative for the vortex flights (Table 3 ).

Figure 8 also shows that a Rayleigh fraction model with an apparent fractionation constant $\varepsilon_{\mathrm{app}}=16 \%$ (average value for the vortex flights) actually fits the general evolution of the entire dataset well (including the lower mixing ratios). This is equivalent to the observation that the data fall approximately on a straight line in a Rayleigh fractionation plot Fig. 4. However, the Rayleigh model attributes the vertical mixing and isotope ratio changes to chemistry only, which is conceptually inadequate given that transport time scales are slower than chemical timescales in the lower and middle stratosphere, as described above.

To investigate the role of mixing across the polar vortex, Kaiser et al. (2006) presented a simple advective-diffusive model of continuous weak mixing after Plumb et al. (2000) and showed that this model leads to a qualitatively similar trace in a Keeling plot as we find in Fig. 8. In that analysis, 


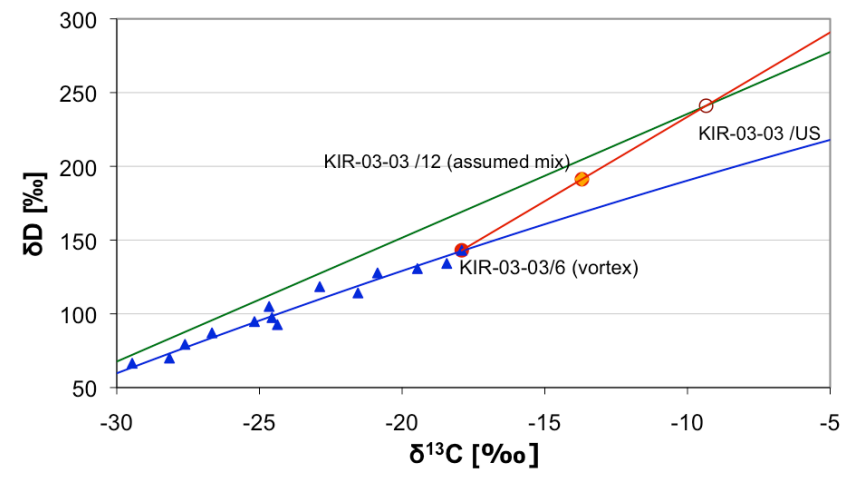

Fig. 9. Assuming that KIR-03-03/12 is the result of an end-member mixing process between vortex air (blue) and upper stratospheric air outside the vortex (green), an appropriate upper stratospheric member KIR-03-03/US can be constructed. Note that the vortex and upper stratospheric end members may shift along the respective lines.

also samples from high-altitude aircraft flights that crossed the vortex edge horizontally were analyzed. Continuous weak mixing will certainly also affect our samples taken near the vortex edge, but a set of isolated vertical balloon profiles is less adequate to investigate this in detail.

Mixing of chemically different air masses across the polar vortex edge, in combination with descent of air from the mesosphere (see next section) is likely responsible for the remaining variability around the average isotope-mixing ratio correlation curve. The corresponding deviations are spatially and/or temporally confined and therefore result in a scatter. Points falling below the average curve represent air parcels that have experienced more than average mixing or less chemical fractionation. The opposite is true for points above the curve. In general, the interpretation of the $\mathrm{CH}_{4}$ isotope signals is in agreement with the situation as discussed for $\mathrm{N}_{2} \mathrm{O}$ (Kaiser et al., 2006).

\subsection{Mesosphere-stratosphere exchange in the vortex}

It was already discussed above that the isotope:isotope correlation is different for mid-latitude and vortex samples Fig. 3. The correlation for the mid latitudes is practically linear. The correlation for the vortex samples becomes successively flatter, i.e. it has lower $\delta \mathrm{D}$ for a given $\delta^{13} \mathrm{C}$ value. Based on the KIE values in Table 1 this can be tentatively attributed to stronger removal by $\mathrm{O}\left({ }^{1} \mathrm{D}\right)$ for the vortex samples, since the reaction of $\mathrm{CH}_{4}$ with $\mathrm{O}\left({ }^{1} \mathrm{D}\right)$ has the lowest $\mathrm{KIE}^{\mathrm{D}}$. The vortex samples have descended from high altitudes where removal by $\mathrm{O}\left({ }^{1} \mathrm{D}\right)$ is expected to be relatively more important. The vortex region is generally characterized by subsidence of air from higher altitudes in the stratosphere and additionally mesospheric air can subside into the stratospheric polar vortex. For flight KIR-03-03, this has been investigated in detail in Engel et al. (2006), and it is interesting to note that the samples that were characterized there as having mesospheric influence do not show unusual behaviour in our isotope-isotope correlations. This suggests that the influence of mesospheric air on $\mathrm{CH}_{4}$ in the vortex is not an exception in 2003 as it looks in the individual profiles, but that the descent of mesospheric air causes the general deviation of the isotope-isotope correlation in the vortex from the one at mid latitudes.

Surprisingly, the sample right below the mesospheric intrusion (KIR-03-03/12) deviates from this general classification. In Table 8 this sample is compared to sample KIR-03$03 / 6$, which is the most enriched sample of the vortex branch of the isotope-isotope correlation, and clearly influenced by mesospheric air (Engel et al., 2006). Although KIR-03-03/06 contains less methane than KIR-03-03/12, i.e. it has undergone more methane removal, it is less enriched. This can be explained if KIR-03-03/12 has been processed more strongly by sink process with strong $\mathrm{KIE}$, namely $\mathrm{Cl}$. We propose that sample KIR-03-03/12, represents air that originates from the upper stratosphere, likely close to the stratopause, and from outside the vortex, which descends to the middle and lower stratosphere below the mesospheric intrusion.

Based on the previous results of this mesospheric air discussed in Engel et al. (2006) and the specific position of KIR-03-03/12 between the two characteristic lines in the isotope:isotope plot (Fig. 9), it can be speculated that sample KIR-03-03/12 is a result of an end-member mixing between the most enriched air sample on the vortex branch, i.e. KIR-03-03/6, and a suitable (unknown) end member from the upper stratosphere, denoted KIR-03-03/US. As the products of mixing are found on a straight line connecting the two end members, the unknown upper stratospheric member must also fall on an extrapolated line through KIR-03$03 / 6$ (on the vortex branch) and KIR-03-03/12. We can further assume that KIR-03-03/US falls on the extrapolation of the mid-latitudinal isotope-isotope correlation (Fig. 9). The intersection then defines the isotopic composition of KIR03-03/US under the given assumptions as given in Table 8 . In this case, it is also straightforward to determine the relative contributions of the two end-members as $45 \%$ of KIR$03-03 /$ US and $55 \%$ of KIR-03-03/6. Note that these relative fractions are slightly dependent on the choice of the end members on the vortex and mid latitude lines, since the vortex line has a curvature.

\section{Conclusions}

Measurements of the ${ }^{13} \mathrm{C}$ and $\mathrm{D}$ content of $\mathrm{CH}_{4}$ on a large set of stratospheric air samples collected over a period of $16 \mathrm{yr}$ provide the most comprehensive picture so far on the isotopic composition of stratospheric $\mathrm{CH}_{4}$. A method to take into account the residence time in the stratosphere in combination with the observed mixing ratio and isotope trends in the troposphere has been presented. The highest 
Table 8. Comparison of two samples from flight KIR-03-03, where mesospheric air was sampled. KIR-03-03/6 is found on the vortex branch of the isotope:isotope relation. It is evident that KIR-03-03/12 must have experienced a different fractionation/mixing history. Although its methane mixing ratio is higher than that of KIR-03-03/6, it is much more enriched. Interpreting KIR-03-03/12 as a result of mixing between vortex air and upper stratospheric air from mid latitudes, an appropriate upper stratospheric end-member is reconstructed (KIR-03-03/US).

\begin{tabular}{|c|c|c|c|c|c|c|c|c|}
\hline $\begin{array}{l}\text { KIR-03-03 } \\
\#\end{array}$ & $\begin{array}{l}\text { altitude } \\
\mathrm{km}\end{array}$ & \multicolumn{2}{|c|}{$\begin{array}{c}c \\
\mathrm{ppb}\end{array}$} & \multicolumn{2}{|c|}{$\begin{array}{c}\delta^{13} \mathrm{C} \\
\% o\end{array}$} & \multicolumn{2}{|c|}{$\begin{array}{l}\delta \mathrm{D} \\
\% \circ\end{array}$} & \\
\hline 6 & 23.9 & 271 & 1.8 & -17.91 & 0.14 & 143.1 & 11 & vortex sample, mesospheric influence \\
\hline 12 & 22.5 & 291 & 0.4 & -13.70 & 0.67 & 191.3 & 2.4 & $\operatorname{mix}$ \\
\hline US & $\sim 40^{*}$ & 314 & & -9.35 & & 241.1 & & hypothetical mid-latitudinal upper stratosphere \\
\hline
\end{tabular}

* Estimated from typical mid-latitude profile

isotope enrichments are found in the polar vortex with values up to $\delta^{13} \mathrm{C}=-19 \%$ and $\delta \mathrm{D}=+190 \%$, strongly extending the range of isotope enrichments observed before. The previously available isotope data from different laboratories and on air samples collected at different locations and times can be linked and compared by relating them to the new large dataset. It also becomes apparent that inter-laboratory differences exist, especially for $\delta \mathrm{D}$.

It has been shown that care has to be taken when mean kinetic isotope effects derived from single balloon profiles are compared. Due to the non-linearity of the isotope-mixing ratio relation in a Rayleigh fractionation plot the samples at the lowest mixing ratio have the strongest leverage on the overall slope. Therefore, only profiles that cover the same range of mixing ratios should be compared directly. If profiles from different times are compared, the temporal mixing ratio and isotope trends also need to be taken into account.

Isotope-isotope correlations show that samples from the polar vortex are less depleted in $\delta \mathrm{D}$ than at mid-latitudes, which is attributed to enhanced chemical destruction by $\mathrm{O}\left({ }^{1} \mathrm{D}\right)$ for the vortex samples. A critical analysis of methods to derive a sink partitioning from global mean kinetic isotope effects is carried out. The classical formal sink partitioning, which is based on the assumption that all sinks act simultaneously, underestimates the contribution from $\mathrm{OH}$, because the KIE values derived in the stratosphere are less influenced by the removal in the lower stratosphere compared to the upper stratosphere. Therefore, global models that include the isotopic composition are needed to derive a reliable sink partitioning from the measurements, similar to the study by McCarthy et al. (2003).

\section{Appendix A}

\section{Tropospheric trend correction by mean age}

Kida (1983) introduced the concept of stratospheric "mean age". This concept describes a stratospheric air mass as a collection of individual isolated air parcels. Each parcel has been transported on its own path associated with a character-

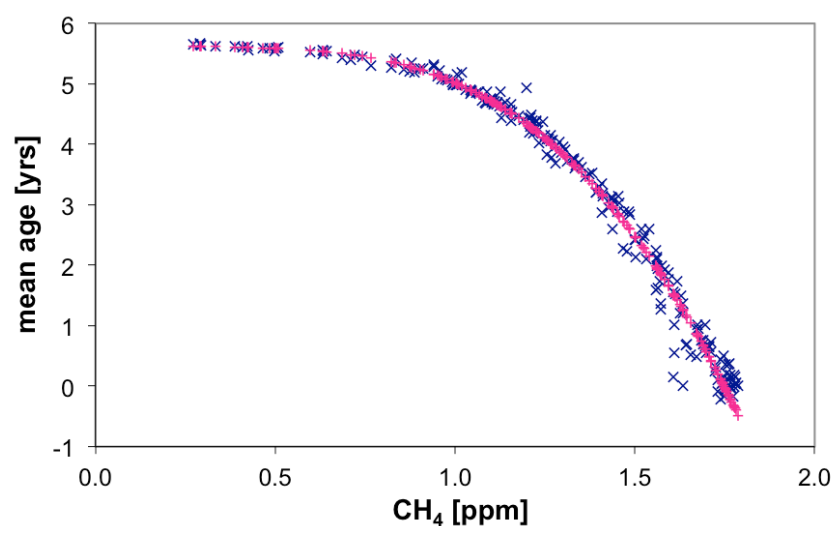

Fig. A1. Stratospheric mean age plotted versus $\mathrm{CH}_{4}$ mixing ratio (red, "+"). The original age inferred from the $\mathrm{N}_{2} \mathrm{O}$ mixing ratio is shown in blue (" $x$ ")

istic transport time and thus the air mass has a spectrum of transport times, of which the mean value defines the mean (stratospheric) age. The age distribution is quite sharp for lower stratospheric tropical air and gets wider towards higher altitudes and latitudes (for further details see Hall and Plumb, 1994; Waugh and Rong, 2002, and references therein).

When the stratospheric mean age is known and the atmospheric trend can be approximated by a linear function, the Rayleigh fractionation Eq. (2) can be modified as:

$\ln \left(\frac{\delta+1}{\delta_{\mathrm{T}}\left(t_{\mathrm{S}}-\Gamma\right)+1}\right)=\left(\frac{1}{\mathrm{KIE}}-1\right) \ln \left(\frac{c}{c_{\mathrm{T}}\left(t_{\mathrm{s}}-\Gamma\right)}\right)$

where $\Gamma$ is the mean age of the sample, $t_{\mathrm{s}}$ the date of sampling and $\delta_{\mathrm{T}}(t)$ and $c_{\mathrm{T}}(t)$ the tropospheric time series of the $\delta$ value and mixing ratio.

$\mathrm{N}_{2} \mathrm{O}$ is a well-suited age indicator for several reasons. It has primarily surface sources and a very small (negligible) seasonal variation. Moreover, it is inert in the troposphere and long-lived in the stratosphere. The tropospheric mixing ratio $c\left(\mathrm{~N}_{2} \mathrm{O}\right)_{\mathrm{T}}$ increases to a good approximation linearly in time, thus it is well-defined and well-known. The stratospheric mean age for most samples presented here was 
already derived from the $\mathrm{N}_{2} \mathrm{O}$ measurements by Kaiser et al. (2006), yielding the formula:

$$
\begin{aligned}
& \Gamma_{\mathrm{N}_{2} \mathrm{O}}\left(\frac{c\left(\mathrm{~N}_{2} \mathrm{O}\right)}{c\left(\mathrm{~N}_{2} \mathrm{O}\right)_{T}}\right)=-(7.43 \pm 0.34)\left(\frac{c\left(\mathrm{~N}_{2} \mathrm{O}\right)}{c\left(\mathrm{~N}_{2} \mathrm{O}\right)_{T}}\right)^{3} \\
& \quad+(3.68 \pm 0.56)\left(\frac{c\left(\mathrm{~N}_{2} \mathrm{O}\right)}{c\left(\mathrm{~N}_{2} \mathrm{O}\right)_{T}}\right)^{2} \\
& \quad-(1.94 \pm 0.28)\left(\frac{c\left(\mathrm{~N}_{2} \mathrm{O}\right)}{c\left(\mathrm{~N}_{2} \mathrm{O}\right)_{T}}\right)+(5.69 \pm 0.04) y r
\end{aligned}
$$

where $c\left(\mathrm{~N}_{2} \mathrm{O}\right)$ is the $\mathrm{N}_{2} \mathrm{O}$ mixing ratio measured in the stratosphere and $c\left(\mathrm{~N}_{2} \mathrm{O}\right)_{\mathrm{T}}$ is its value in the troposphere. $c\left(\mathrm{~N}_{2} \mathrm{O}\right)_{T}$ is calculated from the mean annual trend observed at Mace Head (AGAGE), Ireland, from April 1994 to September 2003, derived from monthly averaged $\mathrm{N}_{2} \mathrm{O}$ mixing ratio measurements.

$$
c\left(\mathrm{~N}_{2} \mathrm{O}\right)_{\mathrm{T}}\left(t_{\mathrm{s}}\right)=0.765 \mathrm{ppbyr}^{-1} \cdot\left(t_{\mathrm{s}}-1994\right)+311.21 \mathrm{ppb}(\mathrm{A} 2)
$$

Based on the $\mathrm{N}_{2} \mathrm{O}$ derived mean age $\left(\Gamma_{\mathrm{N}_{2} \mathrm{O}}\right)$, a relation between $\mathrm{CH}_{4}$ mixing ratio and $\Gamma_{\mathrm{N}_{2} \mathrm{O}}$ (Fig. A1) is derived and then used to interpolate $\Gamma$ from the $\mathrm{CH}_{4}$ mixing ratio, when $\mathrm{N}_{2} \mathrm{O}$ data are missing. Neglecting the small (here negligible) methane trend, the mean age (in years) derived this way is:

$\Gamma_{\mathrm{CH}_{4}}=-2.131 c^{3}+2.460 c^{2}-1.1 c+5.788$

where $\mathrm{c}$ is the $\mathrm{CH}_{4}$ mixing ratio in ppm. Some slightly negative values for $\Gamma_{\mathrm{CH}_{4}}$ relate to samples with mixing ratios slightly higher than the assumed tropospheric background values. Those samples are either from the troposphere or samples strongly influenced by tropospheric air and/or seasonal variation in $\mathrm{CH}_{4}$ mixing ratio. The negative ages $\Gamma_{\mathrm{CH}_{4}}$ do not lead to major changes in mean KIE. To stay consistent for all samples in Fig. A1 only $\Gamma_{\mathrm{CH}_{4}}$ is used in the following. The differences between $\Gamma_{\mathrm{CH}_{4}}$ and $\Gamma_{\mathrm{N}_{2} \mathrm{O}}$ do not cause significant changes in the determination of KIE. The tropospheric $\mathrm{CH}_{4}$ trend $c_{\mathrm{T}}(t)$ used in (A1) is constructed from measurements at Mace Head, Ireland, $40^{\circ} \mathrm{N}$ between May 1994 and September 2003 (Simpson et al., 2002), extrapolated back to 1984 with growth rates from (Dlugokencky et al., 1998), yielding

$c_{\mathrm{T}}\left(\mathrm{CH}_{4}\right)=k_{\mathrm{O}}+k_{1} \cdot \mathrm{yr}+k_{2} \cdot \mathrm{yr}^{2}$

with values of $k_{0}=-1766.707 \mathrm{ppb}, k_{1}=1766.723 \mathrm{ppb} / \mathrm{yr}$, $k_{2}=-0.441245 \mathrm{ppb} \mathrm{yr}^{-2}$. Temporal isotope trends are derived from the upper tropospheric samples of our dataset and calculated relative to the tropospheric sample HYD-99$04 / 3\left(c=1766 \mathrm{ppb}, \delta^{13} \mathrm{C}=-47.30 \%\right.$ and $\delta \mathrm{D}=-81.3 \%$ ) on reference date $t_{\text {ref }}=1999.445$ (26 April 1999).

$$
\begin{aligned}
\delta^{13} \mathrm{C}_{\mathrm{T}}(t) & =-47.30 \% \circ+0.034 \% / \mathrm{yr} \cdot\left(t-t_{\mathrm{ref}}\right) \\
\delta \mathrm{D}_{\mathrm{T}}(t) & =-81.3 \% \circ+0.86 \% \circ / \mathrm{yr} \cdot\left(t-t_{\mathrm{ref}}\right)
\end{aligned}
$$

The $\delta$ values are reported versus the international standards Vienna PeeDeeBelemnite (VPDB) for $\delta^{13} \mathrm{C}$ and Vienna Standard Mean Ocean Water (VSMOW) for $\delta \mathrm{D}$. The mean age corrected KIE values derived this way are rather insensitive to parameter changes. Of course, the magnitudes of tropospheric $\delta$-trends are of relevance. Further the correction is sensitive to the shape of the function that describes the mean age relation $\Gamma_{\mathrm{CH}_{4}}$, whereas shifting $\Gamma_{\mathrm{CH}_{4}}$ by $\pm 1 \mathrm{yr}$ or stretching it for 1 additional year does not significantly change the results.

Acknowledgements. This project was funded by the German BmBF in the AFO 2000 program (project ISOSTRAT) and the Dutch NWO (grant number 865.07.001).

Edited by: M. Dameris

\section{References}

Andrews, A. E., Boering, K. A., Wofsy, S. C., Daube, B. C., Jones, D. B., Alex, S., Loewenstein, M., Podolske, J. R., and Strahan, S. E.: Empirical age spectra for the midlatitude lower stratosphere from in situ observations of $\mathrm{CO}_{2}$ : Quantitative evidence for a subtropical "barrier" to horizontal transport, J. Geophys. Res., 106, 10257-10274, 2001.

Avallone, L. M. and Prather, M. J.: Photochemical evolution of ozone in the lower tropical stratosphere, J. Geophys. Res., 101, 1457-1461, 1996.

Bergamaschi, P., Brühl, C., Brenninkmeijer, C. A. M., Saueressig, G., Crowley, J. N., Grooss, J. U., Fischer, H., and Crutzen, P. J.: Implications of the large carbon kinetic isotope effect in the reaction $\mathrm{CH}_{4}+\mathrm{Cl}$ for the ${ }^{13} \mathrm{C} /{ }^{12} \mathrm{C}$ ratio of stratospheric $\mathrm{CH}_{4}$, Geophys. Res. Lett., 23, 2227-2230, 1996.

Bergamaschi, P., Brenninkmeijer, C. A. M., Hahn, M., Röckmann, T., Scharffe, D. H., Crutzen, P. J., Elansky, N. F., Belikov, I. B., Trivett, N. B. A., and Worthy, D. E. J.: Isotope analysis based source identification for atmospheric $\mathrm{CH}_{4}$ and $\mathrm{CO}$ across Russia using the Trans-Siberian railroad, J. Geophys. Res., 103, 82278235, 1998.

Bergamaschi, P., Bräunlich, M., Marik, T., and Brenninkmeijer, C. A. M.: Measurements of the carbon and hydrogen isotopes of atmospheric methane at Izana, Tenerife: Seasonal cycles and synoptic-scale variations, J. Geophys. Res., 105, 14531-14546, 2000.

Bergamaschi, P., Lowe, D. C., Manning, M. R., Moss, R., Bromley, T., and Clarkson, T. S.: Transects of atmospheric $\mathrm{CO}, \mathrm{CH}_{4}$, and their isotopic composition across the Pacific: Shipboard measurements and validation of inverse models, J. Geophys. Res. 106, 7993-8011, 2001.

Birner, T. and Bönisch, H.: Residual circulation trajectories and transit times into the extratropical lowermost stratosphere, Atmos. Chem. Phys., 11, 817-827, doi:10.5194/acp-11-817-2011, 2011.

Bönisch, H., Engel, A., Birner, Th., Hoor, P., Tarasick, D. W., and Ray, E. A.: On the structural changes in the Brewer-Dobson circulation after 2000, Atmos. Chem. Phys., 11, 3937-3948, doi:10.5194/acp-11-3937-2011, 2011.

Boering, K. A., Wofsy, S. C., Daube, B. C., Schneider, H. R., Loewenstein, M., and Podolske, J. R.: Stratospheric mean ages and transport rates from observations of carbon dioxide and nitrous oxide, Science, 274, 1340-1343, 1996.

Brass, M. and Röckmann, T.: Continuous-flow isotope ratio mass spectrometry method for carbon and hydrogen isotope measure- 
ments on atmospheric methane, Atmos. Meas. Tech., 3, 17071721, doi:10.5194/amt-3-1707-2010, 2010.

Brenninkmeijer, C. A. M., Lowe, D. C., Manning, M. R., Sparks, R. J., and Velthoven, P. F. J. v.: The ${ }^{13} \mathrm{C},{ }^{14} \mathrm{C}$, and ${ }^{18} \mathrm{O}$ isotopic composition of $\mathrm{CO}, \mathrm{CH}_{4}$ and $\mathrm{CO}_{2}$ in the higher southern latitudes lower stratosphere, J. Geophys. Res., 100, 26163-26172, 1995.

Brenninkmeijer, C. A. M., Müller, R., Crutzen, P. J., Lowe, D. C., Manning, M. R., Sparks, R. J., and Velthoven, P. J. v.: A large ${ }^{13} \mathrm{CO}$ deficit in the lower Antarctic stratosphere due to "ozone hole" chemistry: Part 1, observations, Geophys. Res. Lett., 23, 2125-2128, 1996.

Brewer, A. W.: Evidence for a world circulation provided by the measurements of helium and water vapour distribution in the stratosphere, Q. J. Roy. Meteorol. Soc., 75, 351-363, 1949.

Dlugokencky, E. J., Masarie, K. A., Lang, P. M., and Tans, P. P.: Continuing decline in the growth rate of the atmospheric methane burden, Nature, 393, 447-450, 1998.

Dlugokencky, E. J., Myers, R. C., Lang, P. M., Masarie, K. A., Crotwell, A. M., Thoning, K. W., Hall, B. D., Elkins, J. W., and Steele, L. P.: Conversion of NOAA atmospheric dry air $\mathrm{CH}_{4}$ mole fractions to a gravimetrically prepared standard scale, J. Geophys. Res., 110, D18306, doi:18310.11029/12005jd006035, 2005.

Dobson, G. M. B., Brewer, A. W., and Cwilong, B. M.: Meteorology of the lower stratosphere, P. Roy. Soc London Ser-A, 185, 144-175, 1946

Engel, A., Möbius, T., Haase, H.-P., Bönisch, H., Wetter, T., Schmidt, U., Levin, I., Reddmann, T., Oelhaf, H., Wetzel, G., Grunow, K., Huret, N., and Pirre, M.: Observation of mesospheric air inside the arctic stratospheric polar vortex in early 2003, Atmos. Chem. Phys., 6, 267-282, doi:10.5194/acp-6-2672006, 2006.

Erikson, E.: Deuterium and oxygen-18 in precipitation and other natural waters: Some theoretical considerations, Tellus, 17, 498$512,1965$.

Gierzak, T., Talukdar, R. K., Herndon, S. C., Vaghjiani, G. L., and Ravishankara, A. R.: Rate coefficients for reactions of hydroxyl radicals with methane and deuterated methanes, J. Phys. Chem., 101, 3125-3134, 1997.

Griffith, D. W. T., Toon, G. C., Sen, B., Blavier, J.-F., and Toth, R. A.: Vertical profiles of nitrous oxide isotopomer fractionation measured in the stratosphere, Geophys. Res. Lett., 27, 24852488,2000

Gupta, M., Tyler, S., and Cicerone, R.: Modeling atmospheric $\delta^{13} \mathrm{CH}_{4}$ and the causes of recent changes in atmospheric $\mathrm{CH}_{4}$ amounts, J. Geophys. Res., 101, 22923-22932, 1996.

Hall, T. M. and Plumb, R. A.: Age as a diagnostic of stratospheric transport, J. Geophys. Res., 99, 1059-1070, 1994.

Holton, J. R.: A dynamically based transport parameterization for one-dimensional photochemical models of the stratosphere, J. Geophys. Res., 91, 2681-2686, doi:10.1029/JD091iD02p02681, 1986.

Irion, F. W., Moyer, E. J., Gunson, M. R., Rinsland, C. P., Yung, Y. L., Michelsen, H. A., Salawitch, R. J., Chang, A. Y., Newchurch, M. J., Abbas, M. M., Abrams, M. C., and Zander, R.: Stratospheric observations of $\mathrm{CH}_{3} \mathrm{D}$ and HDO from ATMOS infrared solar spectra: Enrichments of deuterium in methane and implications for HD, Geophys. Res. Lett., 23, 2381-2384, 1996.
Kaiser, J., Brenninkmeijer, C. A. M., and Röckmann, T.: Intramolecular ${ }^{15} \mathrm{~N}$ and ${ }^{18} \mathrm{O}$ fractionation in the reaction of $\mathrm{N}_{2} \mathrm{O}$ with $\mathrm{O}\left({ }^{1} \mathrm{D}\right)$ and its implications for the stratospheric $\mathrm{N}_{2} \mathrm{O}$ isotope signature, J. Geophys. Res., 107, 4214, doi:10.1029/2001JD001506, 2002a.

Kaiser, J., Röckmann, T., and Brenninkmeijer, C. A. M.: Temperature dependence of isotope fractionation in $\mathrm{N}_{2} \mathrm{O}$ photolysis, Phys. Chem. Chem. Phys., 4, 4420-4430, doi:4410.1039/b204837j, 2002b.

Kaiser, J., Engel, A., Borchers, R., and Röckmann, T.: Probing stratospheric transport and chemistry with new balloon and aircraft observations of the meridional and vertical $\mathrm{N}_{2} \mathrm{O}$ isotope distribution, Atmos. Chem. Phys., 6, 3535-3556, doi:10.5194/acp6-3535-2006, 2006.

Kaye, J. A.: Mechanisms and observations for isotope fractionation of molecular-species in planetary atmospheres, Rev. Geophys., 25, 1609-1658, 1987.

Keppler, F., Hamilton, J. T. G., Brass, M., and Röckmann, T.: Methane emissions from terrestrial plants under aerobic conditions, Nature, 439, 187-191, doi:110.1038/nature04420, 2006.

Keppler, F., Hamilton, J. T. G., McRoberts, W. C., Vigano, I., Brass, M., and Röckmann, T.: Methoxyl groups of plant pectin as a precursor of atmospheric methane: evidence from deuterium labelling studies, New Phytol., 178, 808-814, 2008.

Kida, H.: General-circulation of air parcels and transport characteristics derived from a hemispheric GCM, 2. Very long-term motions of air parcels in the troposphere and stratosphere, J. Meteorol. Soc. Jap., 61, 510-522, 1983.

Lowe, D. C., Manning, M. R., Brailsford, G. W., and Bromley, A. M.: The 1991-1992 atmospheric methane anomaly: Southern hemisphere C-13 decrease and growth rate fluctuations, Geophys. Res. Lett., 24, 857-860, 1997.

Mahlman, J. D., Levy II, H., and Moxim, W. J.: Three-dimensional simulations of stratospheric $\mathrm{N}_{2} \mathrm{O}$ : Predictions for other trace constituents., J. Geophys. Res., 91, 2687-2707. (Correction, J. Geophys. Res., 2691, 9921, doi:10.1029/JD091iD02p02687, 1986.

McCarthy, M. C., Connell, P., and Boering, K. A.: Isotopic fractionation of methane in the stratosphere and its effect on free tropospheric isotopic compositions, Geophys. Res. Lett., 28, $3657-$ 3660, 2001.

McCarthy, M. C., Boering, K. A., Rice, A. L., Tyler, S. C., Connell, P., and Atlas, E.: Carbon and hydrogen isotopic compositions of stratospheric methane: 2. Two-dimensional model results and implications for kinetic isotope effects, J. Geophys. Res., 108, 4461, doi:10.1029/2002JD003183, 2003.

Michelsen, H. A., Manney, G. L., Gunson, M. R., Rinsland, C. P., and Zander, R.: Correlations of stratospheric abundances of $\mathrm{CH}_{4}$ and $\mathrm{N}_{2} \mathrm{O}$ derived from ATMOS measurements, Geophys. Res. Lett., 25, 2777-2780, 1998.

Miller, J. B., Mack, K. A., Dissly, R., White, J. W. C., Dlugokencky, E. J., and Tans, P. P.: Development of analytical methods and measurements of ${ }^{13} \mathrm{C} /{ }^{12} \mathrm{C}$ in atmospheric $\mathrm{CH}_{4}$ from the NOAA/CMDL global air sampling network, J. Geophys. Res., 107, 4178, doi:4110.1029/2001JD000630, 2002.

Neu, J. L. and Plumb, R. A.: Age of air in a "leaky pipe" model of stratospheric transport, J. Geophys. Res., 104, 19243-19255, 1999.

Park, S. Y., Atlas, E. L., and Boering, K. A.: Measurements of $\mathrm{N}_{2} \mathrm{O}$ isotopologues in the stratosphere: Influence of trans- 
port on the apparent enrichment factors and the isotopologue fluxes to the troposphere, J. Geophys. Res., 109, D01305, doi:01310.01029/02003JD003731, 2004.

Plumb, R. A.: A “tropical pipe" model of stratospheric transport, J. Geophys. Res., 101, 3957-3972, 1996.

Plumb, R. A. and Ko, M. K. W.: Interrelationships between mixing ratios of long lived stratospheric constituents, J. Geophys. Res., 97, 10145-10156, 1992.

Plumb, R. A., Waugh, D. W., and Chipperfield, M. P.: The effects of mixing on traces relationships in the polar vortices, J. Geophys. Res., 105, 10047-10062, 2000.

Quay, P., Stutsman, J., Wilbur, D., Snover, A., Dlugokencky, E., and Brown, T.: The isotopic composition of atmospheric methane, Global Biogeochem. Cy., 13, 445-461, 1999.

Rahn, T., Zhang, H., Wahlen, M., and Blake, G. A.: Stable isotope fractionation during ultraviolet photolysis of $\mathrm{N}_{2} \mathrm{O}$, Geophys. Res. Lett., 25, 4489-4492, 1998.

Rice, A. L., Gotoh, A. A., Ajie, H. O., and Tyler, S. C.: Highprecision continuous-flow measurement of $\delta^{13} \mathrm{C}$ and $\delta D$ of atmospheric $\mathrm{CH}_{4}$, Anal. Chem., 73, 4104-4110, 2001.

Rice, A. L., Tyler, S. C., McCarthy, M. C., Boering, K. A., and Atlas, E.: Carbon and hydrogen isotopic compositions of stratospheric methane: 1. High-precision observations from the NASA ER-2 aircraft, J. Geophys. Res., 108, 4460, doi:10.1029/2002JD003042, 2003.

Ridal, M. and Siskind, D. E.: A two-dimensional simulation of the isotopic composition of water vapor and methane in the upper atmosphere, J. Geophys. Res., 107, 4807, doi:4810.1029/2002JD002215, 2002.

Röckmann, T., Kaiser, J., Brenninkmeijer, C. A. M., Crowley, J. N., Borchers, R., Brand, W. A., and Crutzen, P. J.: Isotopic enrichment of nitrous oxide $\left({ }^{15} \mathrm{~N}^{14} \mathrm{NO},{ }^{14} \mathrm{~N}^{15} \mathrm{NO},{ }^{14} \mathrm{~N}^{14} \mathrm{~N}^{18} \mathrm{O}\right)$ in the stratosphere and in the laboratory, J. Geophys. Res., 106, 1040310410, 2001.

Saueressig, G., Bergamaschi, P., Crowley, J. N., Fischer, H., and Harris, G. W.: Carbon kinetic isotope effect in the reaction of $\mathrm{CH}_{4}$ with $\mathrm{Cl}$ atoms, Geophys. Res. Lett., 22, 1225-1228, 1995.

Saueressig, G., Bergamaschi, P., Crowley, J. N., Fischer, H., and Harris, G. W.: D/H kinetic isotope effect in the reaction $\mathrm{CH}_{4}+$ Cl, Geophys. Res. Lett., 23, 3619-3622, 1996.

Saueressig, G., Crowley, J. N., Bergamaschi, P., Brühl, C., Brenninkmeijer, C. A. M., and Fischer, H.: Carbon 13 and D kinetic isotope effects in the reactions of $\mathrm{CH}_{4}$ with $\mathrm{O}\left({ }^{1} \mathrm{D}\right)$ and $\mathrm{OH}$ : New laboratory measurements and their implications for the isotopic composition of stratospheric methane, J. Geophys. Res., 106, 23127-23138, 2001.

Schmidt, U., Kulessa, G., Klein, E., Roth, E. P., Fabian, P., and Borchers, R.: Intercomparison of balloon-borne cryogenic whole air samplers during the Map-Globus 1983 campaign, Planet. Space Sci., 35, 647-656, 1987.

Simpson, I. J., Blake, D. R., Rowland, F. S., and Chen, T. Y.: Implications of the recent fluctuations in the growth rate of tropospheric methane, Geophys. Res. Lett., 29, 1479, doi:10.1029/2001GL014521, 2002.

Stevens, C. M. and Rust, F. E.: The carbon isotopic composition of atmospheric methane, J. Geophys. Res., 87, 4879-4882, 1982.
Sugawara, S., Nakazawa, T., Shirakawa, Y., Kawamura, K., and Aoki, S.: Vertical profile of the carbon isotopic ratio of stratospheric methane over Japan, Geophys. Res. Lett., 24, 29892992, 1997.

Tarasova, O. A., Brenninkmeijer, C. A. M., Assonov, S. S., Elansky, N. F., Röckmann, T., and Brass, M.: Atmospheric $\mathrm{CH}_{4}$ along the Trans-Siberian railroad (TROICA) and river Ob: Source identification using stable isotope analysis, Atmos. Environ., 40, 56175628, 2006.

Toyoda, S., Yoshida, N., Urabe, T., Aoki, S., Nakazawa, T., Sugawara, S., and Honda, H.: Fractionation of $\mathrm{N}_{2} \mathrm{O}$ isotopomers in the stratosphere, J. Geophys. Res., 106, 7515-7522, 2001.

Tyler, S. C., Ajie, H. O., Gupta, M. L., Cicerone, R. J., Blake, D. R., and Dlugokencky, E. J.: Stable carbon isotopic composition of atmospheric methane: A comparison of surface level and free tropospheric air, J. Geophys. Res., 104, 13895-13910, 1999.

Vigano, I., Röckmann, T., Holzinger, R., van Dijk, A., Keppler, F., Greule, M., Brand, W. A., Geilmann, H., and van Weelden, H.: The stable isotope signature of methane emitted from plant material under UV irradiation, Atmos. Environ., 43, 5637-5646, doi:5610.1016/j.atmosenv.2009.5607.5046, 2009.

Vigano, I., Holzinger, R., Keppler, F., Greule, M., Brand, W. A., Geilmann, H., van Weelden, H., and Röckmann, T.: Water drives the deuterium content of the methane emitted from plants, Geochim. Cosmochim. Act., 74, 3865-3873, 2010.

Volk, C. M., Elkins, J. W., Fahey, D. W., Dutton, G. S., Gilligan, J. M., Loewenstein, M., Podolske, J. R., Chan, K. R., and Gunson, M. R.: Quantifying transport between the tropical and midlatitude lower stratosphere, Science, 272, 1763-1768, 1996.

Wahlen, M.: The Global Methane Cycle, Annu. Rev. Earth Planet. Sci., 21, 407-426, 1993.

Wahlen, M., Tanaka, N., Henty, R., Deck, B., Zeglen, J., Vogel, J. S., Southon, J., Shemesh, A., Fairbanks, R., and Broecker, W.: Carbon-14 in methane sources and in atmospheric methane: The contribution from fossil carbon, Science, 245, 286-290, 1989.

Wang, J. S., McElroy, M. B., Spivakovsky, C. M., and Jones, D. B. A.: On the contribution of anthropogenic $\mathrm{Cl}$ to the increase in $\delta^{13} \mathrm{C}$ of atmospheric methane, Global Biogeochem. Cy., 16, 1047, doi:1010.1029/2001GB001572, 2002.

Waugh, D. W. and Rong, P. P.: Interannual variability in the decay of lower stratospheric Arctic vortices, J. Meteorol. Soc. Japan, 80, 997-1012, 2002.

Waugh, D. W., Plumb, R. A., Elkins, J. W., Fahey, D. W., Boering, K. A., Dutton, G. S., Volk, C. M., Keim, E., Gao, R. S., Daube, B. C., Wofsy, S. C., Loewenstein, M., Podolske, J. R., Chan, K. R., Proffitt, M. H., Kelly, K., Newman, P. A., and Lait, L. R.: Mixing of polar vortex air into middle latitudes as revealed by tracer-tracer scatterplots, J. Geophys. Res., 102, 13119-13134, 1997.

WMO: (World Meteorological Organization), Scientific assessment of ozone depletion: 2002, Global Ozone Research and Monitoring Project, Report Nr 47, Geneva, 498 pp., 2003.

Zahn, A., Franz, P., Bechtel, C., Grooß, J.-U., and Röckmann, T.: Modelling the budget of middle atmospheric water vapour isotopes, Atmos. Chem. Phys., 6, 2073-2090, doi:10.5194/acp-62073-2006, 2006. 